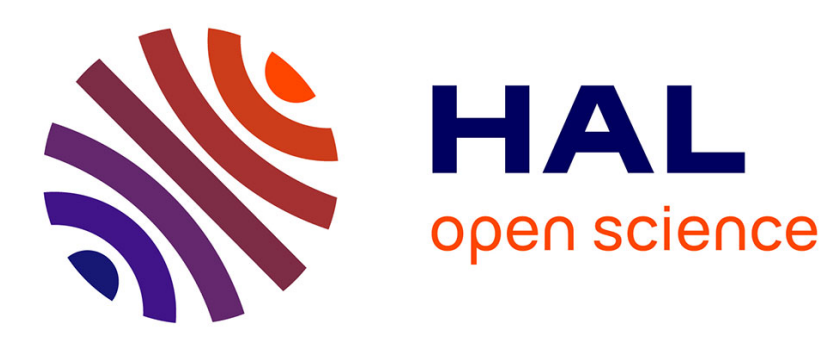

\title{
Physical properties obtained from measurement model analysis of impedance measurements
}

Hangqi Liao, William Watson, Arthur Dizon, Bernard Tribollet, Vinvent

Vivier, Mark Orazem

\section{- To cite this version:}

Hangqi Liao, William Watson, Arthur Dizon, Bernard Tribollet, Vinvent Vivier, et al.. Physical properties obtained from measurement model analysis of impedance measurements. Electrochimica Acta, 2020, 354, pp.136747. 10.1016/j.electacta.2020.136747 . hal-02907090

\section{HAL Id: hal-02907090 \\ https://hal.sorbonne-universite.fr/hal-02907090}

Submitted on 27 Jul 2020

HAL is a multi-disciplinary open access archive for the deposit and dissemination of scientific research documents, whether they are published or not. The documents may come from teaching and research institutions in France or abroad, or from public or private research centers.
L'archive ouverte pluridisciplinaire HAL, est destinée au dépôt et à la diffusion de documents scientifiques de niveau recherche, publiés ou non, émanant des établissements d'enseignement et de recherche français ou étrangers, des laboratoires publics ou privés. 


\title{
Physical Properties Obtained from Measurement Model Analysis of Impedance Measurements
}

\author{
Hangqi Liao ${ }^{a}$, William Watson ${ }^{a}$, Arthur Dizon ${ }^{a}$, Bernard 'Tribollet ${ }^{b}$, Vincent Vivier ${ }^{b}$, Mark E. Orazem ${ }^{a, *}$ \\ "Department of Chemical Engineering, University of Florida, Gainesville, FL 32611 \\ 'Sorbonne Université, CNRS, Laboratoire Interfaces et Systémes Electroniques (LISE), 4 place Jussieu, F-75005, Paris, \\ France
}

\begin{abstract}
The Voigt measurement model is regressed to synthetic data to demonstrate jts ability to extract capacitance, olmic resistance, and polarization resistance values from impedance data. The systems explored include a Randles circuit, films with exponential and power-law distributions of resistivity, systems exhibiting geometric capacitance, and systems showing geometry-induced frequency dispersion. The Voigt measurement model is also regressed to complex capacitance to identify the high-frequency limit in Cole Cole plots. "The measurement model is shown to provide a useful means to estimate properties characteristic of electrochemical systems.
\end{abstract}

Keywonds: simulation, regression, complex capacitance, frequency dispersion

\section{Introduction}

The measurement model was developed in the early $1990 \mathrm{~s}$ as a means to quantify the error structure of electrochemical impedance spectroscopy measurements. Agarwal et al. ${ }^{1}$ demonstrated that a Voigt series can provide an adequate fit to impedance spectra and could therefore serve as a generalized measurement model. By filtering lack of replication of similar impedance spectra, the measurement model was used to identify the standard deviation representing the stochastic error of impedance measurement.s. ${ }^{2}$ The measurement model was also used to jdentify the frequency range of impedance measurements that was consistent with the Kramers-Kronig relations. ${ }^{3,4}$ The theoretical justification for the use of $R C$ elements to approximate impedance spectra was provided by Schönleber and Ivers-Tiffée. ${ }^{5}$ The measurement model approach for assessing consistency was also explored by Boukamp and Macdonald, ${ }^{6}$ and Boukamp developed a linear regression of the Voigt series in which time constants are assigned values based on measured frequencies, leaving a simple linear regression for the corresponding values of resistances. ${ }^{7}$ Schönleber et al. ${ }^{8}$ provided a program that refines the selection of time constants in Boukamp's linear regression approach. ${ }^{7}$

The measurement model concept was explored by Blajiev et al., ${ }^{9,10}$ who suggested that a rational model similar to those used in signal analysis ${ }^{11}$ could be a suitable measurement model. Shukla et al. ${ }^{12}$ used both rational and Voigt measurement models to show that the stochastic error structure identified was independent of the form of the measurement model used. You et al. ${ }^{13}$ showed that the Voigt measurement model as developed by Agarwal et al. ${ }^{1,2,3,4}$ was more sensitive to failures of causality associated with nonstationary behavior than was the linear regression approach pioneered by Boukamp ${ }^{7}$ and implemented by Gamry instruments.

Given that the measurement model could easily fit impedance data that are consistent with the KramersKronig relations, significant effort was made to identify useful information that could be extracted from a measurement model fit to the data. Orazem et al. $^{14}$ showed that the measurement model could yield

*Corresponding author

Email address: meo@che.ufi. edu (Mark E. Orazem) 
estimates for the polarization and ohmic resistances. Their approach was applied, for example, to estimate an upper bound for the rate of corrosion of copper in anaerobic water. ${ }^{15}$ Orazem et al. ${ }^{16}$ used regression of the Voigt measurement model as a means of deconvolution to identify underlying distributions in impedance spectra, and Chen et al. ${ }^{17}$ explored the use of the Voigt measurement model to identify resisitivity distributions in oxide films. Indeed the measurement model was used to determine that a power-law distribution of resistivity in a film gives rise to constant-phase-element (CPE) behavior. ${ }^{18,19}$

It would be useful if the measurement model could also extract capacitance values for electrochemical systems. The evaluation of capacitance is somewhat critical because most electrochemical systems exhibit distributed-time-constant behavior. Often, the analysis of such data employs constant-phase elements (CPE), e.g.

$$
Z_{\mathrm{CPE}}=\frac{1}{(\mathrm{j} \omega)^{\alpha} Q}
$$

where $\mathrm{j}=\sqrt{-1}$ is the imaginary number, $\omega$ is the angular frequency $\left[\mathrm{s}^{-1} \mid\right.$, and, as shown by CordobaTorres et al, ${ }^{20}$ the CPE parameters $\alpha$ and $Q\left[\mathrm{~F} / \mathrm{cm}^{2} \mathrm{~s}^{1-\alpha}\right]$ are highly correlated. The interpretation of the constant-phase element in terms of capacitance requires, in principle, an understanding of the nature of the associated time-constant distribution. ${ }^{21}$ Brug et al. ${ }^{22}$ developed an expression for a surface distribution of time constants that can be expressed as ${ }^{23}$

$$
C_{\mathrm{cff}, \mathrm{surf}}=Q^{1 / \alpha}\left(\frac{R_{\mathrm{c}} R_{\mathrm{t}}}{R_{\mathrm{c}}+R_{\mathrm{t}}}\right)^{(1-\alpha) / \alpha}
$$

where $R_{0}\left[\Omega \mathrm{cm}^{2}\right]$ is the ohmic resistance and $R_{\mathrm{t}}\left[\Omega \mathrm{cm}^{2}\right]$ represents the charge-transfer resistance. Hirschorn et al. $^{24}$ showed that equation (2) applies for geometry-induced frequency dispersion associated with nonuniform current and potential distributions. Hirschorn et al. ${ }^{18,19}$ developed an expression for a distribution of time constants through a film as

$$
C_{\mathrm{E}: \mathrm{ff}, \mathrm{PL}}=g Q\left(\rho_{\delta} \varepsilon \varepsilon_{0}\right)^{1-\alpha}
$$

where $\varepsilon$ is the dielectric constant, $\varepsilon_{0}=8.8542 \times 10^{\cdots 14} \mathrm{~F} / \mathrm{cm}$ is the permitivity of vacuum, $\rho_{\delta}[\Omega \mathrm{cm}]$ is the resistivity at film-electrolyte interface, and

$$
g=1+2.88(1-\alpha)^{2.375}
$$

Orazem et al. ${ }^{23}$ showed that equation (3) applies for a perpendicular distribution of time-constants in a flim. A third approach for interpretation of the CPE parameters can be expressed as

$$
C_{\mathrm{cff}, \mathrm{nom}}=Q^{1 / \alpha} R_{\mathrm{f}}^{(1-\alpha) / \alpha}
$$

where $R_{\|}\left[\Omega \mathrm{cem}^{2}\right]$ is the resistance associated with the are of the depressed semicircle. Equation (5) is equivalent to equation (3) in the work of Hsu and Mansfeld, ${ }^{25}$ presented in terms of the characteristic angular freçuency $\omega_{\max }$. Equation (5) may be applied only under conditions in which the resistance $R_{4}$ is due solely to the properties of the film. In many cases, however, the resistance $R_{\|}$is affected by other factors such as electrochemical reactions or open pores. Orazem et al. ${ }^{23}$ showed that equation (5) did not apply to the apparent CPE response of Imman skin and oxides on steel; whereas, application of equation (3) yielded values for film thickness that agreed with surface analysis with oxides on free-machining $18 / 8$ and martensitic steels. The power-law model has also been applied successfully to characterize oxides on ASTM A416 steels, ${ }^{26}$ oxides on carbon steel, ${ }^{27}$ properties of organic coatings, ${ }^{2 *, 29,30,31.32}$ and properties of oxides on aluminum. ${ }^{33}$

Not all time-constant distributions give rise to a constant-phase element. Young, for exarmple, showed that the impedance of oxides on valve metals can be explained in terms of an exponential distribution of resistivity. ${ }^{34,35}$ Cole-Cole plots, ${ }^{36,37}$ used to extract limiting values for complex relative permittivity, can sometimes be applied to identify capacitance for electrochemical systems. ${ }^{38,39}$

The objective of the present work was to explore the extent to which measurement models may be used to provide a reliable value for the capacitance, ohmic resistance, and polarization resistance of electrochemical systems. The measurement model is applied to synthetic data to explore the conditions under which it will yield reliable values. 


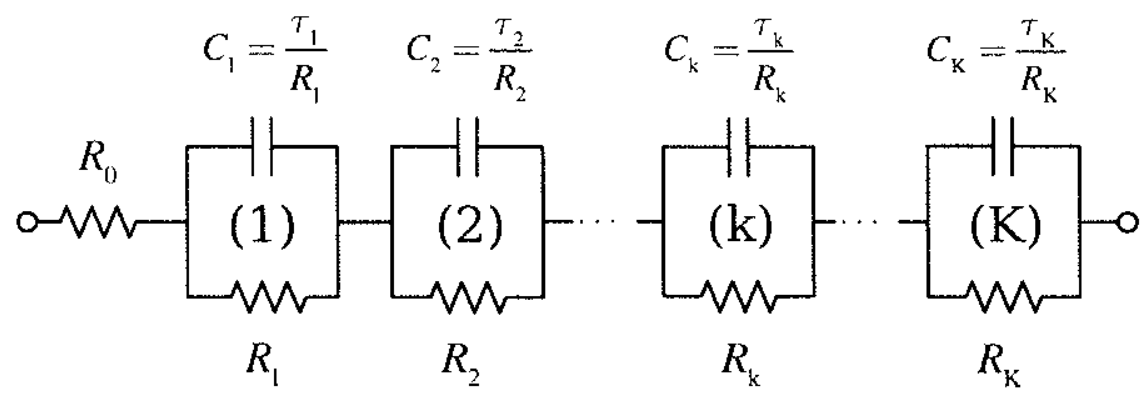

Figure 1: A schematic representation of a Voigt circuit used by Agarwal et al. ${ }^{1,2,4}$ as a measurement model.

\section{Method}

The measurement model proposed by Agarwal et al. ${ }^{1}$ comprises Voigt elements in series with a solution resistance, slown in Figure 1. The impedance of the Voigt circuit can be expressed as

$$
Z=R_{0}+\sum_{\mathrm{k}=1}^{\mathrm{K}} \frac{R_{\mathrm{k}}}{1+j \omega \tau_{\mathrm{k}}}
$$

where the resistance $R_{\mathrm{k}}$ has units of $[\Omega]$ or $\left[\Omega \mathrm{cm}^{2}\right]$ and $\tau_{k}$. has units of $[\mathrm{s}]$. Agarwal et al. ${ }^{1}$ showed that, by including a sufficient number of terms, a general measurement model based on equation (6) can fit impedance data for typical stationary electrochemical systems. The number of Voigt elements $\mathrm{K}$ was increased sequentially under the constraint that the $95.4 \%( \pm 2 \sigma)$ confidence interval for each regressed parameter does not include zero. The same value for $K$ can be obtained by minimization of the Akaike information criterion, which penalizes each additional parameter. ${ }^{40}$

A capacitance for each element $k$ can be expressed as

$$
C_{\mathrm{k}}=\frac{\tau_{\mathrm{k}}}{R_{\mathrm{k}}}
$$

75 where capacitance $C_{\mathrm{k}}$ has units of $\mathrm{F}$ or $\mathrm{F} / \mathrm{cm}^{2}$. In the limit that frequency tends toward infinity,

$$
\lim _{\omega \rightarrow \infty} Z=R_{0}+\sum_{k=1}^{k} \frac{R_{k}}{j \omega \tau_{k}}=R_{0}-\mathrm{j} \sum_{k=1}^{k} \frac{1}{\omega C_{k}}=R_{0}-j \frac{1}{\omega C_{\text {eff }}}
$$

where the effective capacitance can be obtained as

$$
\frac{1}{C_{\text {eff }}}=\sum_{\mathrm{k}} \frac{1}{C_{\mathrm{k}}}
$$

${ }_{n}$ In the limit that frequency tends toward zero, the polarization resistance may be obtained as

$$
\lim _{\omega \rightarrow 0} Z=R_{\mathrm{p}}=R_{0}+\sum_{\mathrm{k}=1}^{\mathrm{K}} R_{\mathrm{k}}
$$

78 The confidence intervals for the effective capacitance and polarization resistance can be obtained from the ig estimated stanciard errors of the regressed parameters using a linear propagation of error analysis (see Section so 3.2 of Orazem and Tribollet ${ }^{41}$ ).

81 Synthetic data were generated by either analytic expressions (Sections 4.1 and 4.2 .1 ), by numerical 82 solution of an integral (Section 4.2.2), or solution of Laplace's equation applied to a potential phasor (Sections 834.3 and 4.4 ). Normally distributed noise was added to the synthetic data, i.e.,

$$
Z_{\mathrm{r}}=Z_{\mathrm{r}, \text { model }}+N_{1}\left(\mu, \sigma^{2}\right)
$$




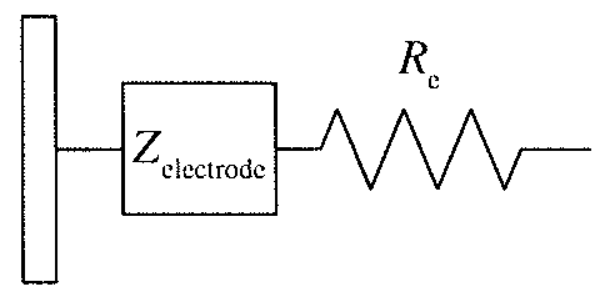

(a)

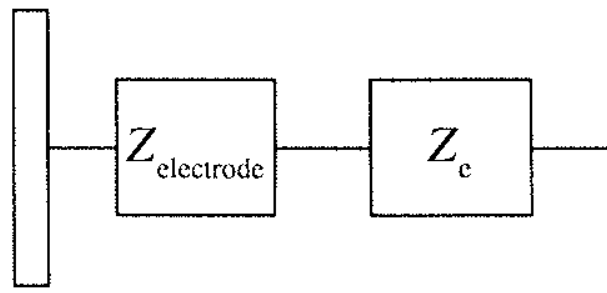

(b)

Figure 2: Schematic representation of an electrochemical electrode-electrolyte interface: a) electrode with a uniform current and potential distribution and b) electrode with a nonuniform geometry-induced current and potential distributison.

84 and

$$
Z_{\mathrm{j}}=Z_{\mathrm{j}, \text { model }}+N_{2}\left(\mu, \sigma^{2}\right)
$$

where the means of independent normal distributions $N_{1}$ and $N_{2}$ had value $\mu=0$.

Equations (11) and (12) are justified by the work of Carson el al., ${ }^{42}$ who showed that, for propagation of additive time-domain errors through an electrochemical cell and the Fourier analysis associated witl typical frequency response analyzers, the errors in the real and imaginary impedance were normally dist.jbuted, uncorrelated, and had equal frequency-dependent standard deviations. The statistical results of Carson et al. ${ }^{42}$ agreed with experimental data collected using a Solartron 1250 frequency response analyzer (FRA) with a Solartron 1286 electrochemical interface for an n-GaAs/W Sclottky diode held at fixed temperatures ranging from 320 to $400 \mathrm{~K} \cdot{ }^{43}$

Carson et al. ${ }^{1 . t}$ also studied propagation of additive time-domain errors 1hrough an electrochemical cell and the mathematics of phase-sensitive detection associated with typical lock-in amplifiers. In contrast to results obtained using the frequency-response analysis algorithm, errors in the real and inaginary impedance were found to be correlated, and the variances of the real and imaginary parts of the complex impedance were not equal under all conditions. For the present work, the standard deviations for the real and imaginary parts of the impedance were assumed to be equal with a value $\sigma=0.002|Z|$, in agreement with experimental observation. ${ }^{41,45}$ Thus, the assumed stochastic error structure was that associated with systems that employ Fourier analysis, such as the Gamry, Solartron, and Autolab instruments.

\section{Regression Approach}

The regressions performed in the present work employed weighted nonlinear complex least-squares regression using a Levenberg-Marquardt algorithm. The regressions were weighted by the inverse of the variance of the assumed stochastic error structure. The original measurement model program was written in the $1990 \mathrm{~s}$ in a combination of FORTAN and Matlab programming languages. The present analysis was performed using a new program written in the Python language and available from the authors as a Windows installation executable. ${ }^{46}$

\section{Results}

Equation (6) was regressed to synthetic data corresponding to a number of typical electrochemical systems. In principle, an electrochemical system may be described in terms of a electrode impedance and the contribution of the electrolyte. The electrochemical systems considered are of two types. In the absence of nonuniform current and potential distributions, the impedance may be expressed as the series combination of a electrode impedance $Z_{\text {electrodo }}$ and an ohmic resistance $R_{e}$, as shown in Figure $2(a)$. In the presence of nonuniform current and potential distributions, caused, for example, by the geometry of an electrode, the ohmic contribution must be expressed in terms of an olmic impedance $Z_{\mathrm{e}}$, as shown in Figure $2(\mathrm{~b})$. 
Table 1: Parameters employed for the electrochemical renction infuenced by mass transfer in a film presented in Figures 33.7 .

$$
\begin{array}{rrl}
\delta_{\mathrm{i}} & 4 \times 10^{-3} & \mathrm{~cm} \\
D_{\mathrm{i}} & 1 \times 10^{-5} & \mathrm{~cm}^{2} / \mathrm{s} \\
C & 2 \times 10^{-5} & \mathrm{~F} / \mathrm{cm}^{2} \\
R_{\mathrm{c}} & 5 & \Omega \mathrm{cm}^{2} \\
R_{\mathrm{t}} & 2.835 & \Omega \mathrm{cm}^{2} \\
R_{\mathrm{d}} & 8.504 & \Omega \mathrm{cm}^{2}
\end{array}
$$

The ohmic impedance may be expressed, as shown by Gharbi et al., ${ }^{33}$ in the form of the Havriliak-Negami equation, ${ }^{47}$ i.e.,

$$
Z_{\mathrm{e}}=R_{\mathrm{e}, \mathrm{HF}}+\frac{R_{\mathrm{e}, \mathrm{LF}}-R_{\mathrm{e}, \mathrm{HF}}}{\left(1+(\mathrm{j} \omega \tau)^{\nu}\right)^{\beta}}
$$

where $\tau$ is the characteristic time constant of the ohnic impedance and the exponents $\nu$ and $\beta$ dictate the limiting phase angles of the ohmic impedance at high and low frequency. Thus, in the presence of a nonuniform current and potential distribution, the influence of the electrolyte may be expressed in terms of two ohmic resistances: $R_{\mathrm{c}, \mathrm{HF}}$ that applies in the high-frequency limit and $R_{\mathrm{c}, L F}$ ihat applies at lower frequencies.

In Section 4.1, the measurement model is applied for a reaction influenced by mass transfer. This example does not account for the complications associated with a nommiform current and potential distribution. It serves to demonstrate that the measurement model yields an accurate estimate for the capacitance and ohmic resistance in spite of the interference caused by the mass-transfer term. The results presented in Section 4.2 for the impedance of a film demonstrate that the measurement model can provide accurate values for capacitance, ohmic, and polarization resistances in the presence of frequency dispersion caused by a distribution of properties in a film. Two examples presented in Section 4.2 are not affected by nonuniform current and potential distributions along the surface of the electrodes. The presentation in Section 4.3 of a geometric capacitance for a disk electrode shows that the information to be obtained by use of the measurement model depends on the frequency range used for the regression. At low frequencies, the influence of ohmic impedance associated with nonuniform current and potential distributions must be considered. The results presented in Section 4.4 for a disk electrode demonstrate that the influence of the ohmic impedance may be avoided by limiting the frequency range regressed by the measurement model. The results presented in Sections 4.1 to 4.4 serve to illustrate the power and the limitations of the use of the measurement model to extract physical properties.

\subsection{Reaction Influenced by Mass Transfer}

Synthetic data were generated for an electrochemical reaction infuenced by mass transfer in a film. The parameters used to generate the data are presented in Table 1. The current was assumed to be three quarters of the mass-transfer-limited current. The frequency range was $10 \mathrm{mHz}-100 \mathrm{kHz}$. The charge-transfer resistance was $R_{\mathrm{t}}=2.835 \Omega \mathrm{cm}^{2}$ and a diffusion resistance was $R_{\mathrm{c}}=8.504 \Omega \mathrm{cm}^{2}$.

The impedance was expressed as

$$
Z=R_{\mathrm{c}}+\frac{R_{\mathrm{t}}+Z_{\mathrm{d}}(\omega)}{1+\mathrm{j} \omega\left(R_{\mathrm{t}}+Z_{\mathrm{d}}(\omega)\right) C}
$$

${ }_{144}$ where $Z_{d}(\omega)$ is the frequency-dependent diffusion impedance. Under the assumption of diffusion through a film, the diffusion impedance can be expressed as

$$
Z_{\mathrm{d}}(\omega)=R_{\mathrm{d}} \frac{\tanh \sqrt{\mathrm{j \omega \delta _{ \textrm {i } } ^ { 2 }} / D_{\mathrm{i}}}}{\sqrt{\mathrm{j} \omega \delta_{\mathrm{i}}^{2} / D_{\mathrm{i}}}}
$$

${ }_{146}$ where $R_{\mathrm{d}}$ is the diffusion resistance. The capacitance, shown in Table 1 , was assigned to have a value of ${ }_{147} C=20 \mu \mathrm{F} / \mathrm{cm}^{2}$. Normally distributed errors were added to the synthetic data with $\sigma_{\mathrm{r}}=\sigma_{\mathrm{j}}=0.002 ! Z \mid$. 


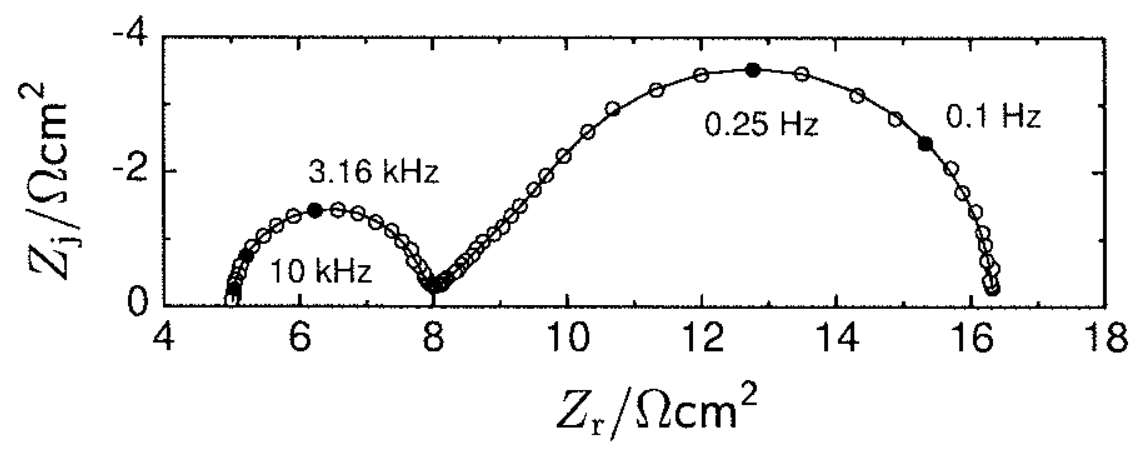

Figure 3: Regression results for synthetic data obtained using the parameters given in Table 1 at three cuarters of the masstransfer-limited current. The line represents the fit of the meastrement model with parameters given in Table 2 .

Table 2: Regression results for the synthetic data shown in Figure 3. The characteristic frecuency for each element is defined as $f_{\mathrm{k}}=1 /\left(2 \pi \tau_{\mathrm{k}}\right)$.

\begin{tabular}{cccccc}
$\mathrm{k}$ & $\tau_{\mathrm{k}} / \mathrm{s}$ & $f_{\mathrm{k}} / \mathrm{Hz}$ & $R_{\mathrm{k}} / \Omega \mathrm{cm}^{2}$ & $C_{\mathrm{k}} / \mu \mathrm{Fcm}^{-2}$ & Contribution \\
\hline 0 & $\cdots$ & - & $5.0065 \pm 0.0027$ & - & $\ldots$ \\
1 & $(5.817 \pm 0.025) \times 10^{-5}$ & 2736 & $2.8607 \pm 0.0070$ & $20.332 \pm 0.099$ & $99.48 \%$ \\
2 & $(1.10 \pm 0.12) \times 10^{-3}$ & 145 & $0.213 \pm 0.014$ & $5180 \pm 650$ & $0.39 \%$ \\
3 & $0.0106 \pm 0.0010$ & 15.0 & $0.422 \pm 0.024$ & $25100 \pm 2800$ & $0.081 \%$ \\
4 & $0.0635 \pm 0.0029$ & 2.51 & $0.939 \pm 0.024$ & $67800 \pm 3500$ & $0.030 \%$ \\
5 & $0.6490 \pm 0.0028$ & 0.245 & $6.887 \pm 0.017$ & $94320 \pm 440$ & $0.021 \%$
\end{tabular}

The resulting synthetic data are presented in Figure 3. The fit of the measurement model to the synthetic data shown in Figure 3 is presented as a solid line, and the resulting parameters are presented in Table 2. The ohmic resistance and capacitance extracted from the regressed parameters are presented in Table 3. The capacitance obtained from the measurement model was $C=20.226$ t $0.098 \mu \mathrm{F} / \mathrm{cm}^{2}$ and the ohmic resistance was $5.0065 \pm 0.0027 \Omega \mathrm{cm}^{2}$. The error in estimation of capacitance was 1.1 percent and the error in estimation of ohmic resistance was 0.13 percent.

Five Voigt elements were used to obtain the fit shown in Figure 3 and Table 2. Use of an additional Voigt element, resulted in parameter estimates that included zero in the $95.4 \%$ confidence interval. Following equations (7) and (9), each Voigt element contributes to the estimated capacitance, but the Voigt elements used to fit the low-frequency diffusion impedance yielded large capacitances and, as shown in Table 2 , correspondingly small contributions to the estimated capacitance. The 1.1 percent error in estimation of capacitance can be attributed largely to the added noise in the synthetic data. Regression of the measurement model to synthetic data without added noise yielded seven Voigt elements and an estimated capacitance of $20.019 \pm 0.038 \mu \mathrm{F} / \mathrm{cm}^{2}$ with an error of 0.093 percent.

The normalized residual errors for the regression shown in Figure 3 and Table 2 are presented in Figure

Table 3: Comparison of values extracted from the measurement model regression to the input parameters for the synthetic data presented in Figures 3, 5, and 7 . Input parameters are given in Table 1.

\begin{tabular}{lccccc} 
Parameter & Input & Measurement Model & Data Type & Figure & Frequency Range \\
\hline$R_{\mathrm{c}} / \Omega \mathrm{cm}^{2}$ & 5 & $5.0065 \pm 0.0027$ & Impedance & 3 & $10 \mathrm{MHz}-100 \mathrm{kHz}$ \\
$C / \mu \mathrm{Fcm}^{-2}$ & 20 & $20.226 \pm 0.098$ & Impedance & 3 & $10 \mathrm{MHz}-100 \mathrm{kHz}$ \\
$C / \mu \mathrm{Fcm}^{-2}$ & 20 & $20.115 \pm 0.025$ & Capacitance & 5 & $1 \mathrm{~Hz}-10 \mathrm{kHz}$ \\
$R_{\mathrm{c}} / \Omega \mathrm{cm}^{2}$ & 5 & $5.0061 \pm 0.0027$ & Impedance & 7 & $1 \mathrm{kHz}-100 \mathrm{kHz}$ \\
$C / \mu \mathrm{Fcm}^{-2}$ & 20 & $20.33 \pm 0.10$ & Impedance & 7 & $1 \mathrm{kHz}-100 \mathrm{kHz}$
\end{tabular}




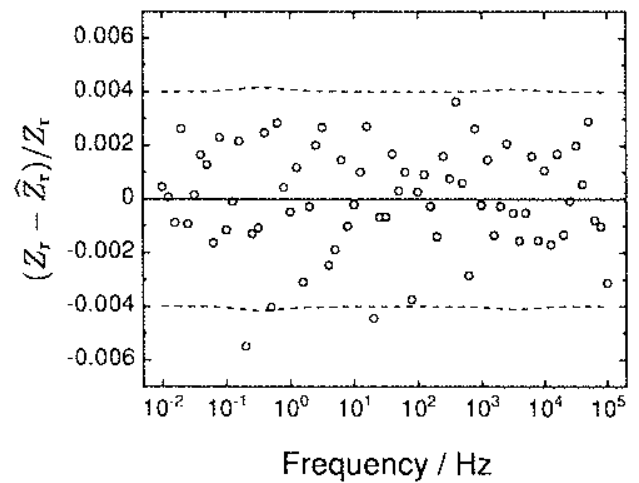

(a)

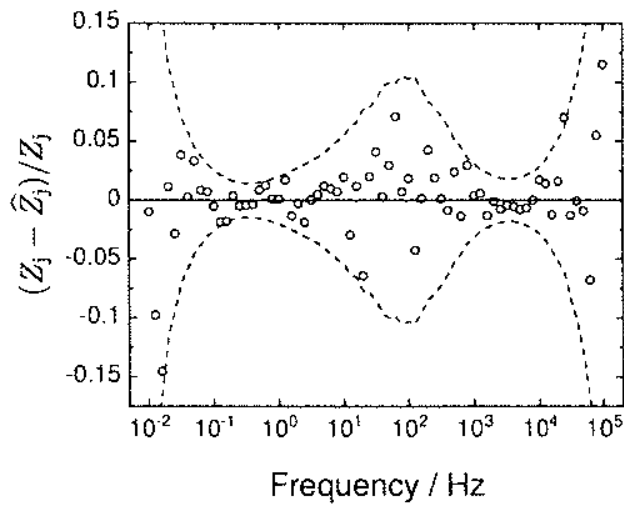

(b)

Figure 4: Normalized residual errors for the regression shown in Figure 3 with parameters show in Table 2: a) real part of the impedance and b) imaginary part of the impedance. Daslied lines represent the $95.4 \%$ interval for the assimed stochaslic error structure, i.e., $\pm 2 \sigma / Z_{\text {, or }} \pm 2 \sigma / z_{i}$, where $\sigma=0.002|Z|$

4 as functions of frequency. The residual errors generally fell within the $95.4 \%$ interval for the assumed error structure. The large values for the normalized residual errors for the imaginary part of the impelance at high and low frequencies, shown in Figure $4(b)$, can be attributed to the small magnitudes of the imaginary part of the impedance. For this regression, the weighted chi squared statistic was close to the degree of freedom $\nu$, i.e., $\chi^{2} / \nu=0.89$, also suggesting an excellent fit. Boukamp ${ }^{48}$ provided an analytic expression for the time constants of a Voigt element applied to a finite-length Warburg impedance as

$$
\tau_{111}=\frac{\tau_{0}}{\pi^{2}(\mathrm{n} 1-0.5)^{2}}
$$

where $\tau_{0}=\delta^{2} / D_{\text {; }}$ and the order of the index $m$ is inverted from that shown for the index $\mathrm{k}$ in Table 2 , i.e., the inde $\mathrm{m}=1$ corresponds to the largest time constant. The value $\tau_{5}=0.6490 \pm 0.0028 \mathrm{~s}$ given in Table 2 is in good agreement with the value $\tau_{1}=0.648$ calculated from equation (16). The resistance $R_{5}=6.887 \pm 0.01752 \mathrm{~cm}^{2}$ is in agreement with Figure 7 of Boukamp. ${ }^{48}$

The Cole-Cole representation ${ }^{36}$ provides an alternative method to extract capacitance. The complex capacitance, obtained as

$$
C^{*}=\frac{1}{j \omega\left(Z-R_{0}\right)}
$$

requires, however, a good estimate for ohmic resistance. ${ }^{32}$ The complex capacitance is presented in Figure 5 with ohmic resistance used in equation (17) as a parameter. The ohmic resistance was varied by $\pm 5 \%$ from the input value of $R_{\mathrm{c}}=5 \Omega \mathrm{cm}^{2}$. The calculation of complex capacitance yielded scattered results at low frequency due to the noise in the synthetic data, and these low-frequency results are not shown in Figure 5. The trending at high-frequency may be attributed in part to the noise in the measurement under conditions that $Z \approx R_{\mathrm{c}}$. In addition, the noise is very large on the imaginary part of the impedance for frequencies above $10 \mathrm{kHz}$. An extrapolation of the complex capacitance to the real axis suggests that an uncertainty of 5 percent in ohmic resistance yields an uncertainty of 20 percent in the capacitance.

The complex capaciance calculated for the input value of $R_{\mathrm{c}}=5 \Omega \mathrm{cm}^{2}$ is presented in Figure 6 . An asymptotic approach to a capacitance near $20 \mu \mathrm{F} / \mathrm{cm}^{2}$ is evident at high frequencies. To facilitate extrapolation of the Cole-Cole plot to the high-frequency limit, the measurement model given as equation (6) was modified for complex capacitance as

$$
\mathcal{C}=C(\infty)+\sum_{\mathrm{k}=1}^{K} \frac{C_{\mathrm{k}}}{1+\mathrm{j} \omega \tau_{\mathrm{k}}}
$$




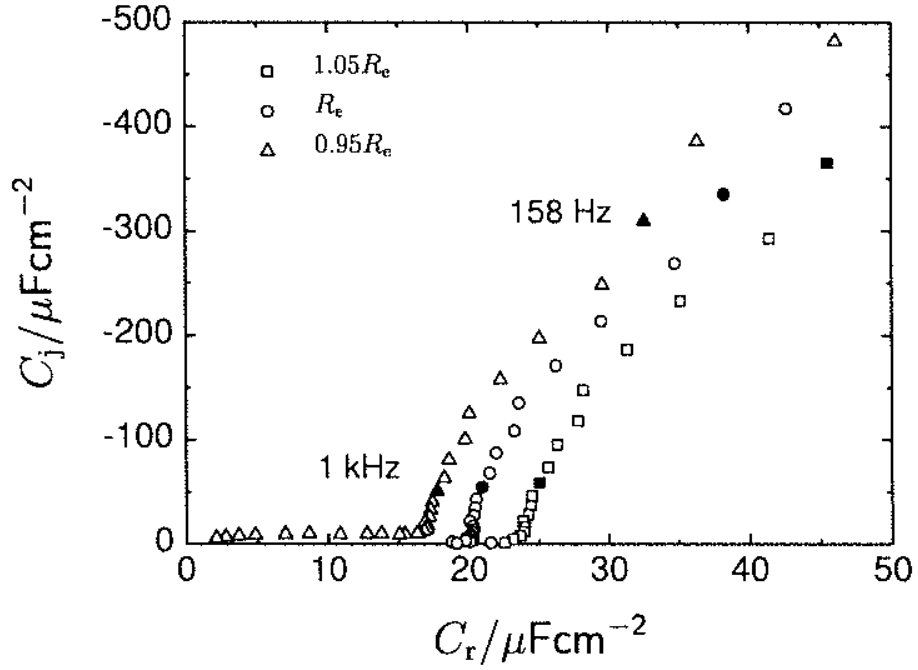

Figure 5: Complex capacitance obtained from the impedance data shown in Figure 3 with assuned ohmic rosistance as a parameter. The maximum frequency shown is $100 \mathrm{kH} r$.

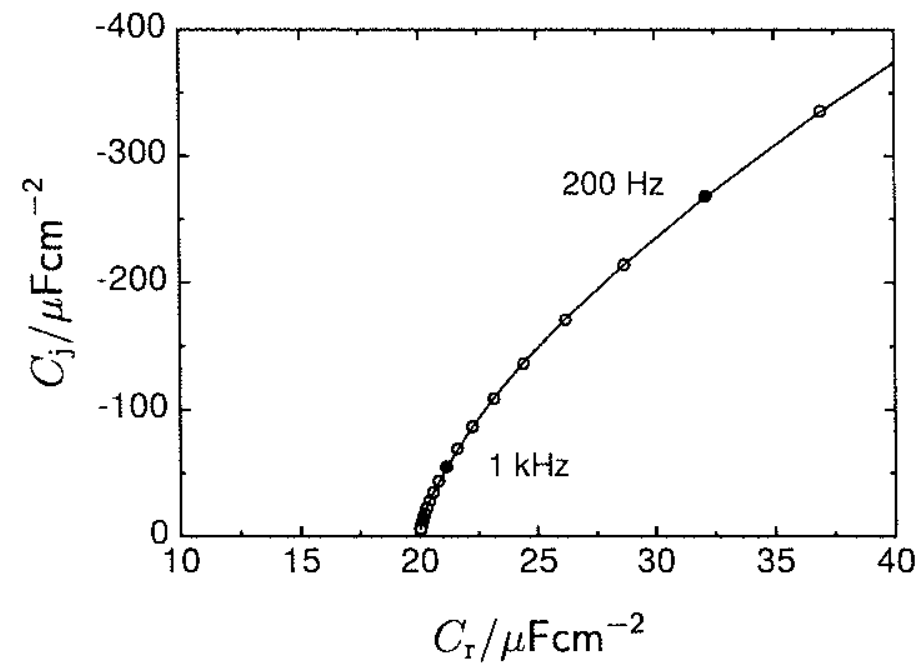

Figure 6: Complex capacitance obtained from the impedance data shown in Figure 3. The maximum frequency shown is $10 \mathrm{kHz}$. An asymptotic approach at high frequencies yields a capacitance near $20 \mu \mathrm{F} / \mathrm{cm}^{2}$. The line is the fit by a modified measurement model given as equation (18) to frequencies between $1 \mathrm{~Hz}$ and $10 \mathrm{kHz}$. 


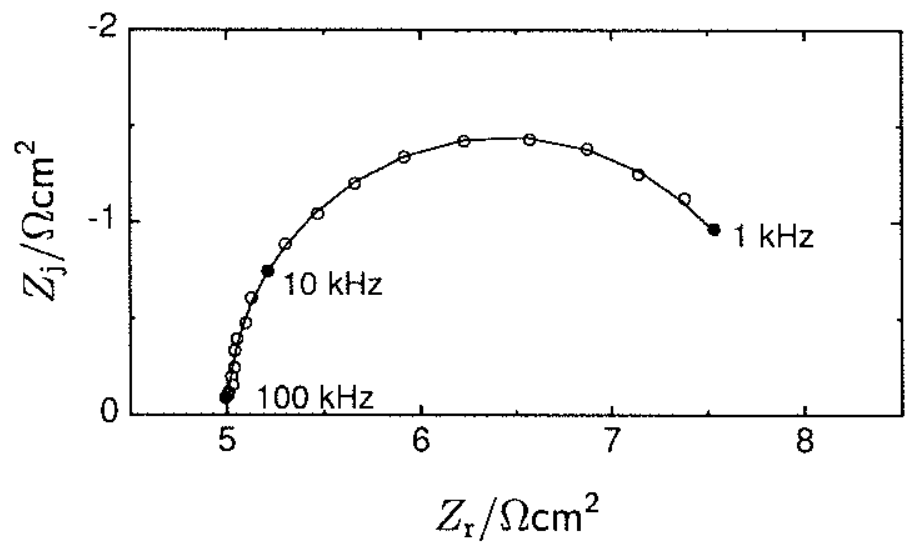

Figure 7: Regression results for synthetic data obtained using the parameters given in Table 1 at three quarters of the masstransfer-limited current. The data were truncated to minimize the contribution of the diffusion impedance. The frequency range was $\mathrm{J}-100 \mathrm{kJl}$, and $x^{2} / \nu=0.86$. The line represents the fit of the measurenent model with parameters given in Table 4.

Table 4: Regression restits for a truncated spectrum shown in Figure 7. Input parameters for $R_{0}\left(\right.$ see $\left.R_{0}\right)$ and $R_{t}$ (see $\left.R_{1}\right)$ are given in Table 1 .

\begin{tabular}{cccccc}
$\mathrm{k}$ & $\tau / \mathrm{s}$ & $f_{\mathrm{k}} / \mathrm{Hz}$ & $R_{\mathrm{k}} / \Omega \mathrm{cm}^{2}$ & $C_{\mathrm{k}} / \mu \mathrm{Fcm}{ }^{2}$ & Contribution \\
\hline 0 & - & - & $5.0061 \pm 0.0027$ & - & - \\
1 & $(5.868 \pm 0.025) \times 10^{-5}$ & 2712 & $2.8866 \pm 0.0075$ & $20.33 \pm 0.10$ & $100 \%$
\end{tabular}

and fit to the synthetic data shown in Figure 6. The fit with four Voigt elements to frequencies between $1 \mathrm{~Hz}$ and $10 \mathrm{kHz}$ is presented as a line in Figure 6. The capacitance estimate from equation (18) was $C(\infty)=20.115 \pm 0.052 \mu \mathrm{F} / \mathrm{cm}^{2}$ with an error of 0.58 percent.

The low-frequency part of the synthetic data shown in Figure 3 was truncated to emphasize the highfrequency part of the measurement. The resulting spectrum, spanning a frequency range from $1 \mathrm{kHz}$ to $100 \mathrm{kHz}$, is presented in Figure 7. Regression of the measurement model to the high-frequency data shown in Figure 7 yielded a single Voigt element, as would be expected for a reaction unaffected by mass transfer. The fit is sbown as a line in Figure 7, and the resulting regressed parameters are presented in Table 4. The results are included in the summary presented in Table 3. The capacitance obtained from the measurement model was $C=20.33 \pm 0.10 \mu \mathrm{F} / \mathrm{cm}^{2}$. The error in estimation of capacitance was 1.6 percent. The ohmic resistance was estimated as $R_{\mathrm{e}}=5.0061 \pm 0.0027 \Omega \mathrm{cm}^{2}$, in good agreement with the value obtained by regression to the complete spectrum shown in Table 2. The value $R_{1}=2.8866 \pm 0.0075 \Omega \mathrm{cm}^{2}$ corresponds to the input value of $R_{\mathrm{t}}=2.835 \Omega \mathrm{cm}^{2}$ given in Table 1 .

\subsection{Distribution of Time Constants in a Film}

Two models are often used to account for frequency dispersion associated with a perpendicular distribution of time constants in a film. Young ${ }^{34}$ applied an exponential distribution of resistivity with respect to the normal distance to the electrode, and Hirschorn et al. ${ }^{18.19}$ developed a model based on a power-law distribution of resistivity.

\subsubsection{Exponential Resistivity Distribution in a Film}

The impedance of the film can be written for an arbitrary resistivity distribution $\rho(y)$ as

$$
Z_{\mathrm{f}}(f)=\int_{0}^{\delta} \frac{\rho(y)}{1+j \omega \varepsilon \varepsilon_{0} \rho(y)} \mathrm{d} y
$$




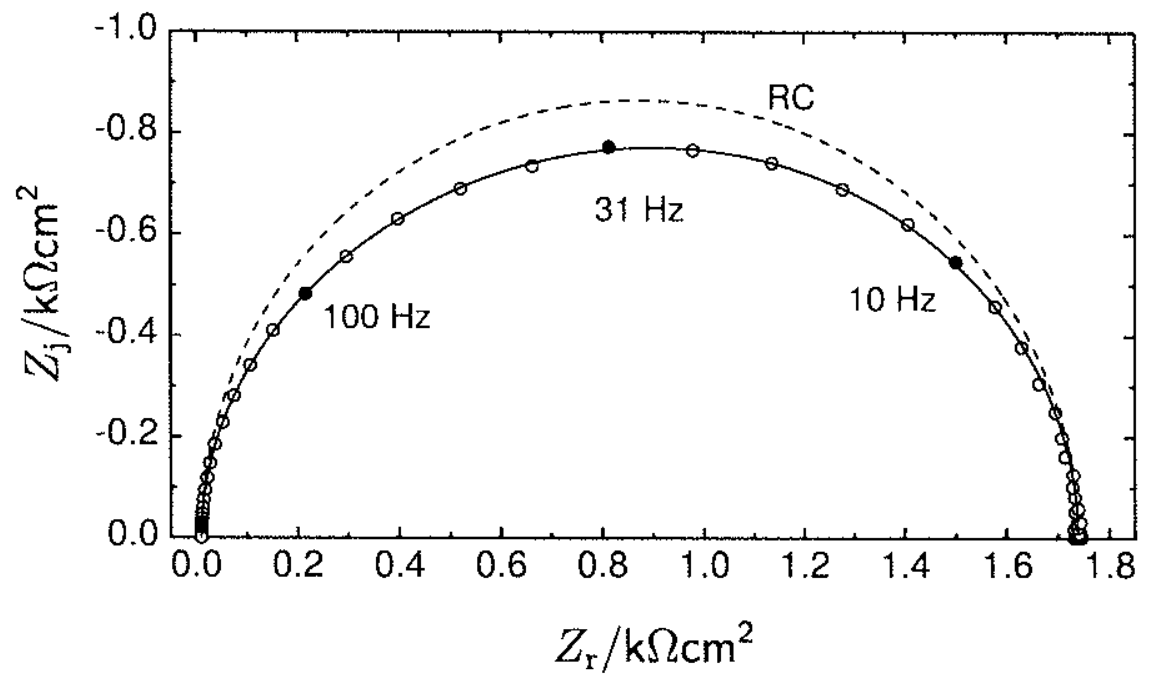

Figure 8: Young impedance given by equation (21) in Nyquist format with $R_{\mathrm{e}}=10 \Omega \mathrm{cm}^{2}, \varepsilon=12, \lambda=2 \mathrm{~nm}, \delta=4 \mathrm{~mm}$, and $\rho_{0}=10^{10} \Omega \mathrm{cm}$. The line represents the measurement model fit with three Voigt elements. The dashed line represents a perfect $R C$ behavior and is presented to higlilight the distortion caused by the Young resistivity distrilution. The frequency rauge was $10 \mathrm{mHz}$ to $100 \mathrm{kHz}$ and $x^{2} / \nu=1.23$.

Young ${ }^{34}$ assumed that the nonstoichiometry of an oxide layer resulted in an exponential variation of the conductivity with respect to the normal distance to the electrode. This assumption may be expressed in terms of resistivity as

$$
\rho(y)=\rho_{0} \exp (-y / \lambda)
$$

The Young impedance for the gradient presented in equation (20) is 24,49,50

$$
Z_{Y}=\frac{\lambda}{j \omega \varepsilon \varepsilon_{0}} \ln \left(\frac{1+j \omega \rho_{0} \varepsilon \varepsilon_{0}}{1+j \omega \rho_{0} \varepsilon \varepsilon_{0} \exp (-\delta / \lambda)}\right)
$$

In the low-frequency limit, application of L'Hôpital's rule yields

$$
\lim _{\omega \rightarrow 0} Z_{\mathrm{Y}}=\lambda \rho_{0}(1-\cdots \exp (-\delta / \lambda))
$$

which corresponds to a resistor. This result is in agreement with the direct integration of resistivity. In the high-frequency limit,

$$
\lim _{\omega \rightarrow \infty} Z_{Y}=-j \frac{\delta}{\omega \varepsilon \varepsilon_{0}}
$$

which corresponds to the impedance of the capacitor

$$
C_{Y}=\frac{\varepsilon \varepsilon_{0}}{\delta}
$$

The measurement model was applied to synthetic data for a film following the Young impedance.

The impedance was calculated as

$$
Z=R_{\mathrm{c}}+Z_{\mathrm{Y}}
$$

and normally distributed stochastic errors were added following equations (11) and (12). The calculated impedance response for $R_{\mathrm{c}}=10 \Omega \mathrm{cm}^{2}, \varepsilon=12, \lambda=2 \mathrm{~mm}, \delta=4 \mathrm{~nm}$, and $\rho_{0}=10^{10} \Omega \mathrm{cm}$ is shown in Figure 8, where the line represents the measurement model fit using three Voigt elements. The dashed line represents a perfect $R C$ behavior and is presented to highlight the distortion caused by the Young resistivity distribution. 
Table 5: Comparison of values extracted from the measurement model regression to the input parameters for the synthetic dat a presented in Figure 8.

\begin{tabular}{lccc} 
Parameter & Input & Source & Measurement Model \\
\hline$R_{\mathrm{c}} / \Omega \mathrm{cm}^{2}$ & 10 & - & $9.9915 \pm 0.0062$ \\
$Z_{\mathrm{Y}}(0) / \Omega \mathrm{cm}^{2}$ & 1729.33 & Equation $(22)$ & $1728 \pm 158$ \\
$C / \mu \mathrm{Fcm}^{-2}$ & 2.65626 & Equation $(24)$ & $2.66 \pm 0.29$
\end{tabular}

235 and

A summary is presented in Table 5 of values extracted from the measurement model regression to the synthetic data presented in Figure 8. The measurement model results are in excellent agreement to the input parameters. 'The error for determination of olmic resistance was $0.085 \%$, the error for determination of $Z_{Y}(0)$ was $0.039 \%$, and the error for determination of capacitance was $0.020 \%$.

\subsubsection{Power-Law Resistivity Distribution in a Film}

Hirschorn et al. ${ }^{18,19}$ showed that a power-law distribution of resistivity corresponds to a constant-phase element, i.e.,

$$
\frac{\rho}{\rho_{\delta}}=\xi^{-\gamma}
$$

where $\xi=y / \delta, y$ represents the position through the depth of the film, and $\delta$ is the film thickness. 'The parameter $\rho_{\delta}$ is the resistivity at $y=\delta$, and $\gamma$ is a constant indicating the sharpness of the variation of resistivity. A distribution of resistivity that provides a bounded value for resistivity at $\xi=0$ was proposed to be

$$
\frac{\rho}{\rho_{\delta}}=\left(\frac{\rho_{\delta}}{\rho_{0}}+\left(1-\frac{\rho_{\delta}}{\rho_{0}}\right) \xi^{\gamma}\right)^{-1}
$$

where $\rho_{0}$ and $\rho_{\delta}$ are the boundary values of resistivity at the respective interfaces. By integration of equation (19), Hirschorn et a]. ${ }^{18,19}$ showed that

$$
Q=\frac{\left(\varepsilon \varepsilon_{0}\right)^{\alpha}}{g \delta \rho_{\delta}^{1-\alpha}}
$$

$$
\alpha=\frac{\gamma-1}{\gamma}
$$

where $g$, defined by equation (4), provided a relationship between the constant-phase-element parameters and the power-law model.

The impedance was calculated following

$$
Z=R_{\mathrm{c}}+Z_{\mathrm{f}}
$$

245 and

and normally distributed stochastic errors were added following equations (11) and (12). The simulations presented in Figure 9 represent the integration of equations (19) and (27) with $\rho_{0}=10^{14} \Omega \mathrm{cm}, \rho_{\delta}=$ $5 \times 10^{6} \Omega \mathrm{cm}, \gamma=6+2 / 3, \varepsilon=12$, and $\delta=2 \mathrm{~mm}$. The ohmic resistance, $R_{\mathrm{e}}=10 \Omega \mathrm{cm}^{2}$, was added following equation (30).

'The results presented in Figure 9(a) suggest a constant-phase-element behavior as suggested by equation (29), from which a value $\alpha=0.85$ is obtained. The impedance response has two characteristic frequencies:

$$
f_{c, 0}=\frac{1}{2 \pi \varepsilon \varepsilon_{0} \rho_{0}}=1.50 \mathrm{~Hz}
$$

$$
f_{c, \delta}=\frac{1}{2 \pi \varepsilon \varepsilon_{0} \rho_{\delta}}=29.96 \mathrm{kHz}
$$

${ }_{246}$ The high-frequency region, presented in Figure 9(b), indicates that the impedance deviates from pure CPE

247 behavior near $f_{c, \delta}$, at which a capacitive behavior is identified. The measurement model results are compared 


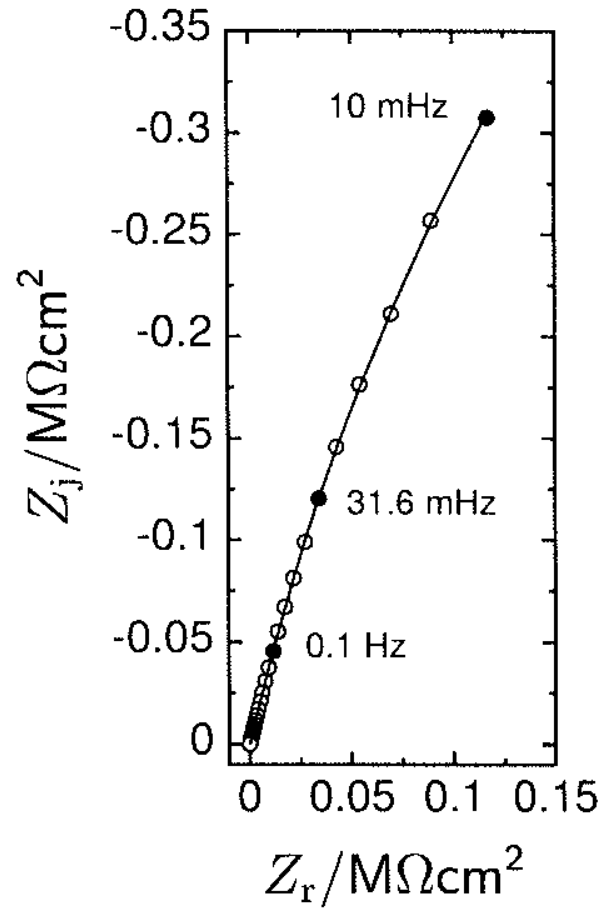

(a)

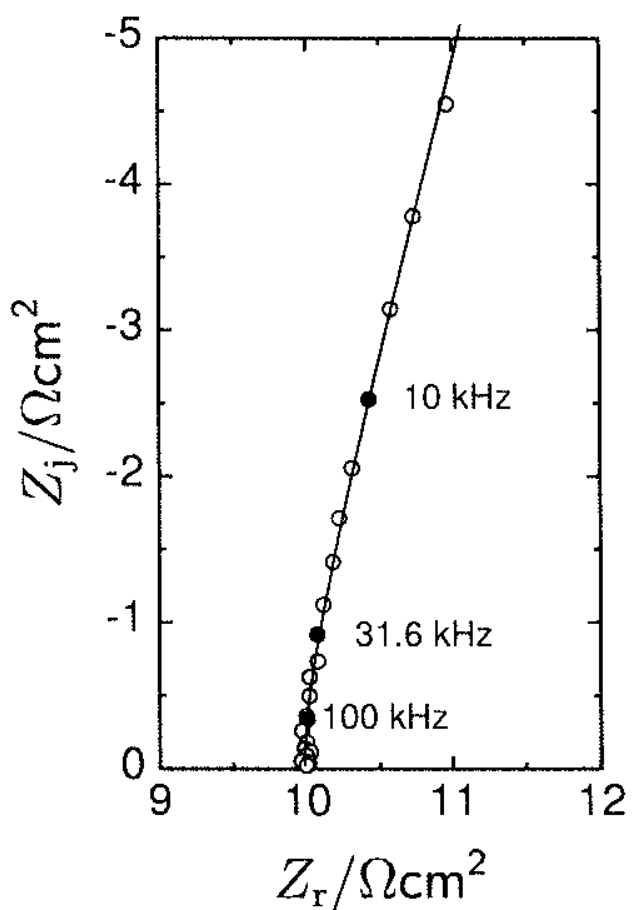

(b)

Figure 9: Impedance given by equations (30) and (19) for the resistivity given by equation $(27)$ with $R_{0}=10 \Omega\left(\mathrm{m}^{2}, \rho_{0}=\right.$ $10^{14} \Omega \mathrm{cm}, \rho_{\delta}=5 \times 10^{6} \Omega \mathrm{cm}, \gamma=6+2 / 3, \varepsilon=12$, and $\delta=2 \mathrm{~mm}$ : a) complete (requency range and is) high frequency range. The line represents the measurement model fit with eleven Voigt elements. The frequency range was $10 \mathrm{mHz}$ to $100 \mathrm{kHz}$ and $x^{2} / \nu=1.09$.

Table 6: Comparison of values extracted from the neasurement model regression to the input parameters for the synthetic data presented in Figure 9.

$\begin{array}{lccc}\text { Parameter } & \text { Input } & \text { Source } & \text { Measurement Model } \\ R_{\mathrm{c}} / \Omega \mathrm{cm}^{2} & 10 & - & 9.9965 \pm 0.0079 \\ C / \mu \mathrm{Fcm}^{-2} & 5.313 & \text { equation (24) } & 5.45 \pm 0.22\end{array}$




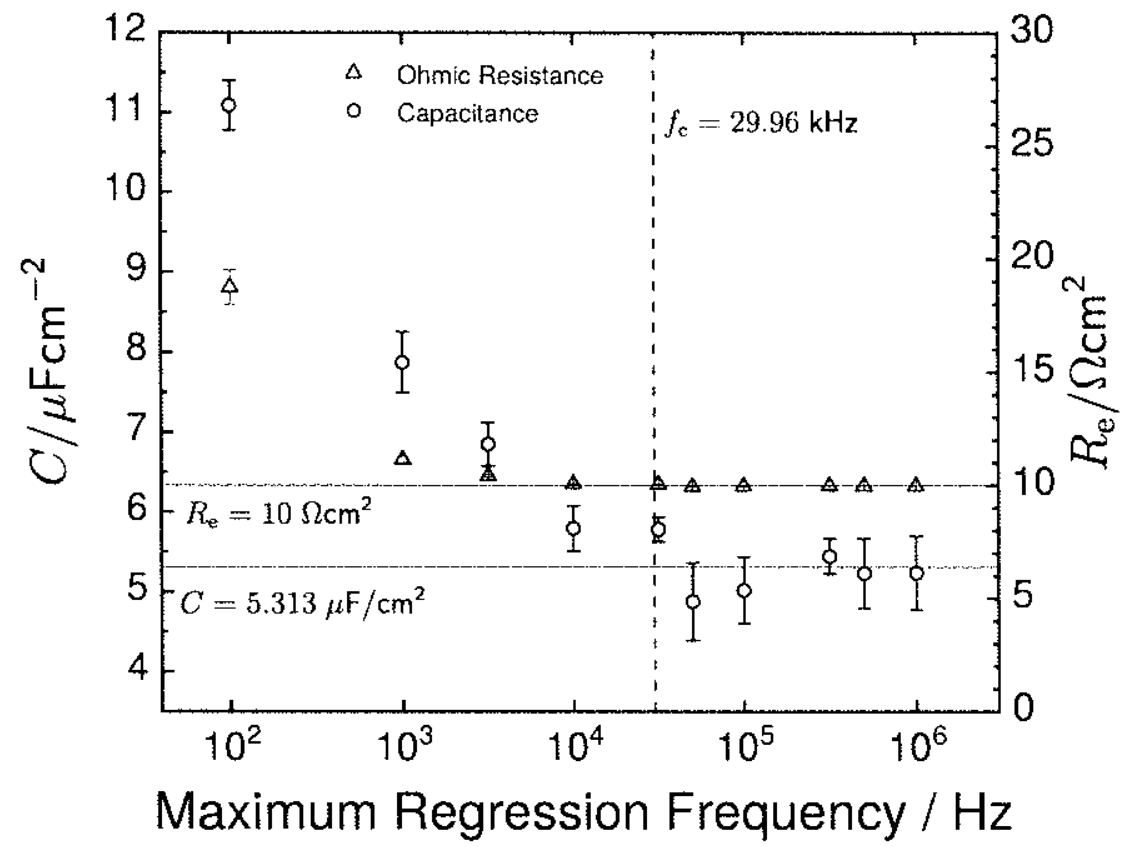

Figure 10: Capacitance obtained by regression of equation (6) to the complex impedance for truncated frequency ranges as functions of the maximum regression frequency of the regressed data. For example, the values of capacitance and ohmic resistance for a maximum regression frequency of $100 \mathrm{~Hz}$ were obtained by regression to data encompasing the frequency range of $10 \mathrm{mHz}$ to $100 \mathrm{~Hz}$.

to the input values in Table 6 . The error for determination of ohmic resistance was $-0.14 \%$ and the error for deternination of capacitance was $-1.38 \%$.

Determination of capacitance was made possible by the high-frequency capacitive belavior seen in Figure 9(b). For systems in which the characteristic frequency defined by equation (32) is larger than the measured frequency range, the impedance has the character of a constant-phase element for which a capacitance camnot be obtained. Thus, capacitance values extracted from the measurement model analysis will be incorrect. Equation (6) was regressed to the complex impedance for truncated frequency ranges. The results are presented in Figure 10. A capacitance of $11.09 \pm 0.31 \mu \mathrm{F} / \mathrm{cm}^{2}$, shown for a maximum regression frequency of $100 \mathrm{~Hz}$, was obtained by regression to data encompassing frequencies from $10 \mathrm{mHz}$ to $100 \mathrm{~Hz}$. The maximum frequency analyzed was smaller than the characteristic frequency given by equation (32), and the resulting capacitance had an error of $109 \%$. Larger errors may be obtained by regression to spectra with still smaller maximum frequencies. A similar error was found for the estimation of the ohmic resistance. The ohmic resistance of $18.74 \pm 0.76 \Omega \mathrm{cm}^{2}$, shown for a maximum regression frequency of $100 \mathrm{~Hz}$, had an error of $87 \%$.

\subsection{Geometric Capacitance}

Numerical simulations using finite elements were performed for a disk olectrode embedded in an insulating plane. The numerical method employed in the present work is described by Dizon and Orazem for interdigitated electrodes. ${ }^{51}$ The appearance of a high-frecuency loop associated with the geometric capactance can be attributed to treatment of displacement as well as electrical currents.

The governing equation was conservation of current density

$$
\nabla \cdot \mathbf{i}=0
$$

where the current density vector $\mathbf{i}$ comprised both electrical and displacement currents, i.e.,

$$
\mathbf{i}=\kappa \mathbf{E}+\frac{\mathrm{d} \mathbf{D}}{\mathrm{d} t}
$$




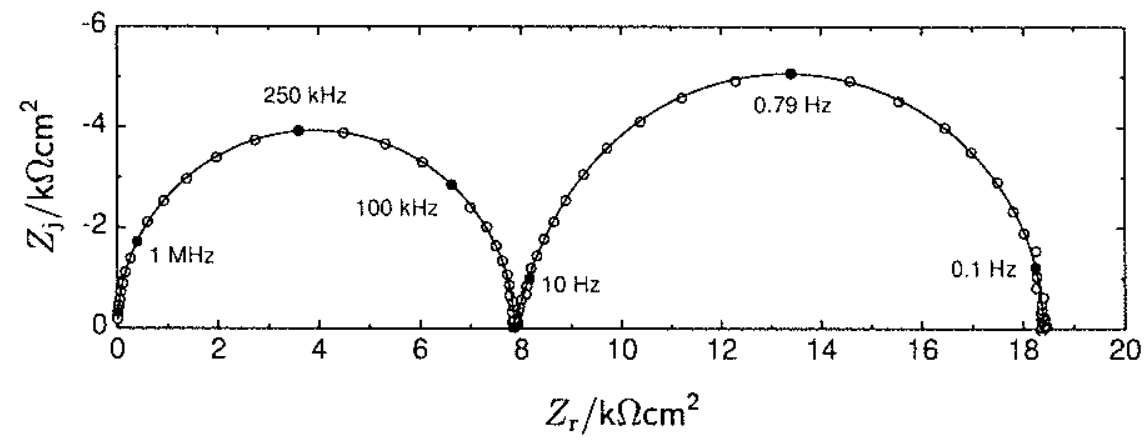

Figure 11: Simulated impedance response for a disk electrode with parameters $T 0=0.1 \mathrm{~cm}, \rho \cdots 10^{5} \Omega \mathrm{cm}, \hat{\epsilon}=78, C_{\mathrm{dl}}=$ $20 \mu \mathrm{F} / \mathrm{cm}^{2}$, and $R_{t}=10^{4} \Omega \mathrm{cm}^{2}$. The line represents the fit by the measurement model with four Voigt elements. The frequency range was ] $m \mathrm{~Hz}-1 \mathrm{MHz}$, and $x^{2} / \nu=1.29$.

where $\kappa$ is the electrical conductivity, $\mathbf{E}$ is the electric field vector, and $\mathbf{D}$ is the electrical displacement vector. The electrical displacement vector was obtained from the constitutive relationship

$$
\mathrm{D}=\varepsilon \varepsilon_{0} \mathrm{E}
$$

and the electric-field vector was related to the electrical potential $\Phi$ by

$$
\mathbf{E}=-\nabla \Phi
$$

Equations (33) $-(36)$ are straightforward applications of Maxwell's equations.5.

The electric potential and current were represented in phasor notation as

$$
\Phi=\widetilde{\Phi}+\operatorname{Re}\left\{\widetilde{\Phi} e^{j\lrcorner t}\right\}
$$

and

$$
\mathbf{i}=\overline{\mathbf{i}}+\operatorname{Re}\left\{\tilde{\mathbf{i}} e^{\mathrm{j} \omega t}\right\}
$$

where $\bar{\Phi}$ and $\overline{\mathbf{i}}$ are the steady-state electrical potential and current density, respectively, and $\widetilde{\Phi}$ and $\tilde{\dot{i}}$ are complex potential and current density phasors, respectively. The phasors $\widetilde{\Phi}$ and $\widetilde{i}$ are functions of frequency and position, but are independent of time.

Under assumptions of a steady state and uniform properties, substitution of equations (34) to (38) into equation (33) yields

$$
\nabla \cdot \overline{\mathbf{i}}=-\kappa \nabla^{2} \bar{\Phi}=0
$$

The conservation of current under a sinusoidal steady-state may be expressed as

$$
\left(1+j \omega \varepsilon \varepsilon_{0} \rho\right) \nabla^{2} \tilde{\Phi}=0
$$

As the permittivity of vacuum $\varepsilon_{0}=8.8542 \times 10^{-14} \mathrm{C} / \mathrm{V} \mathrm{cm}$ is a very small number, equation (40) shows that, for electrolytes of modest resistivity, the contribution of the displacement current can be neglected for impedance measurements in the usual $10 \mathrm{mHz}-100 \mathrm{kHz}$ range. The displacement current plays an important role for measurements performed in high-resistivity electrolytes such as organic liquids. $5.3,54$

Synthetic data are presented in Figure 11 for a disk electrode with parameters $r_{0}=0.1 \mathrm{~cm}, \rho=10^{5} \Omega \mathrm{cm}$, $\varepsilon=78, C_{\mathrm{d} 1}=20 \mu \mathrm{F} / \mathrm{cm}^{2}$, and $R_{t}=10^{4} \Omega \mathrm{cm}^{2}$. Normally distributed stochastic errors were added following equations (11) and (12). The synthetic data reveal a high-frequency loop that can be attributed to the geometric capacitance. The geometric capacitance for a disk electrode may be expressed as

$$
C_{\mathrm{g}}=\frac{4 \varepsilon \varepsilon_{0}}{\pi r_{0}}
$$


Table 7: Conparison of values extracted from the measurement model regression to the input parameters for the synthetic data presented in Figures 3, 5, and 7 .

\begin{tabular}{lcccc} 
Parameter & Input & Measurement Model & Figure & Frequency Range \\
\hline$C_{\mathrm{g}} / \mathrm{nF}^{-2} \mathrm{~cm}^{-2}$ & 0.08793 & $0.088008 \pm 0.000067$ & 11 & $1 \mathrm{mHz}-10 \mathrm{MHz}$ \\
$R_{\mathrm{c}, \mathrm{HF}} / \Omega \mathrm{cm}^{2}$ & 7,854 & $7,855.3 \pm 3.0$ & 11 & $1 \mathrm{mHz}-10 \mathrm{MHz}$ \\
$C_{\mathrm{dl}} / \mu \mathrm{Fcm}-2$ & 20 & $12.0 \pm 1.2$ & $12(\mathrm{a})$ & $1 \mathrm{mHz}-100 \mathrm{~Hz}$ \\
$R_{\mathrm{c}, \mathrm{HF}} / \Omega \mathrm{cm}^{2}$ & 7,854 & $7,879.2 \pm 8.3$ & $12(\mathrm{a})$ & $1 \mathrm{mHz} \cdots 100 \mathrm{~Hz}$ \\
$R_{\mathrm{t}} / \Omega \mathrm{cm}^{2}$ & 10,000 & $10,519 \pm 81$ & $12(\mathrm{a})$ & $1 \mathrm{mHz}-100 \mathrm{~Hz}$ \\
$C_{\mathrm{dl}} / \mu \mathrm{Fcm}^{-2}$ & 20 & $19.50 \pm 0.40$ & $12(\mathrm{~b})$ & $1 \mathrm{mHz}-0.79 \mathrm{~Hz}$ \\
$R_{\mathrm{c}, \mathrm{LF}} / \Omega \mathrm{cm}^{2}$ & - & $8,268 \pm 45$ & $12(\mathrm{~b})$ & $1 \mathrm{mHz}-0.79 \mathrm{~Hz}$ \\
$R_{\mathrm{t}} / \Omega \mathrm{cm}^{2}$ & 10,000 & $10,131 \pm 43$ & $12(\mathrm{~b})$ & $1 \mathrm{mHz} \cdots 0.79 \mathrm{~Hz}$
\end{tabular}

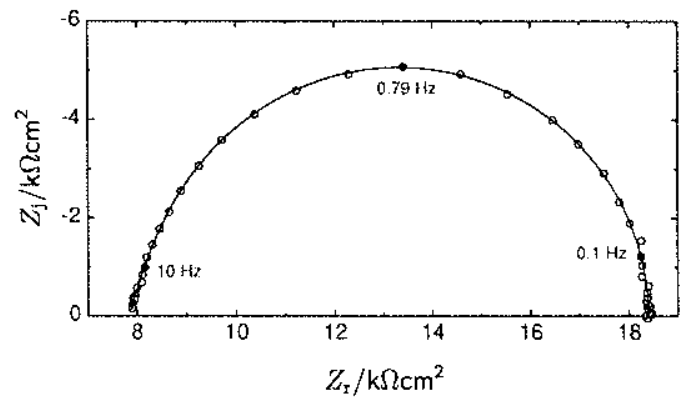

(a)

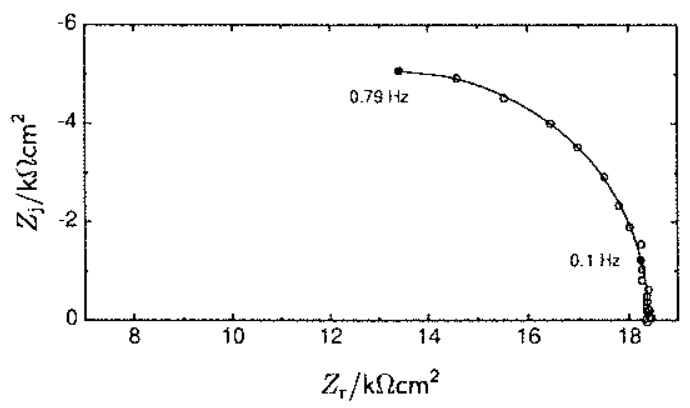

(b)

Figure 12: Truncated impedance taken from Figure 11: a) synthetic data with a frequency range of 1 inHz to $100 \mathrm{~Hz}$ and b) synthetic data with a frequency range of $1 \mathrm{mHz}$ to $0.79 \mathrm{~Hz}$. The lines represent measurement model fits using, respectively, three or one Voigt element, and the respective values of $x^{2} / \nu$ were 1.14 and 1.06 .

where the characteristic dimension for the disk electrode is $\pi r_{0} / 4$.

Regression of the measurement model to the complete spectrum shown in Figure 11 required four Voigt elements. The results are presented in Table 7 . The capaciance was $C_{\mathrm{g}}=0.088008 \pm 0.000067 \mathrm{nF} / \mathrm{cm}^{2}$, in good agreement with the value of $0.08793 \mathrm{nF} / \mathrm{cm}^{2}$ calculated from equation (41). The geometric capacitance loop was fit by a single Voigt element, and the high-frequency ohmic resistance could be obtained from associated resistance value as $R_{\mathrm{e}, \mathrm{HF}}=7,855.3+3.0 \Omega \mathrm{cm}^{2}$, in good agreement with the value of $7,854 \Omega \mathrm{cm}^{2}$ calculated from input parameters.

Regression of the measurement model to the low-frequency capacitive loop, shown in Figure 12(a), required three Voigt elements. The regressed frequency range was $1 \mathrm{mHz}-100 \mathrm{~Hz}$. The results are presented in Table 7. The ohmic resistance obtained was $7,879.2 \pm 8.3 \Omega \mathrm{cm}^{2}$, which was close to the high-frequency olmic resistance estimated from input parameters to be $7,854 \Omega \mathrm{cm}^{2}$. The regression allowed estimation of capacitance, but the value obtained, $12.0 \pm 1.2 \mu \mathrm{Fcm}^{-2}$, was substantially smaller than the input double layer capacitance of $20 \mu \mathrm{Fcm}^{-2}$. Similarly, the charge-transfer resistance was slightly larger than the input value.

The error in estimation of double-layer capacitance and, to a lesser degree, the error in estimation of charge-transfer resistance can be attributed to the frequency dispersion caused by the nonuniform current and potential distribution associated with the disk geometry. The characteristic frequency associated with frequency dispersion has a value ${ }^{55}$

$$
f_{c}=\frac{1}{8 R_{c, \mathrm{HF}} C_{\mathrm{dl}}}=0.796 \mathrm{~Hz}
$$

based on input values of $R_{\mathrm{a}, H F}$ and $C_{\mathrm{al}}$. The results of the regression of the measurement model to the data with frequencies in the range $1 \mathrm{mHz}-0.79 \mathrm{~Hz}$ are shown in Figure 12(b). Only a single Voigt element could be extracted, as would be expected in the absence of frequency dispersion. The capacitance was 


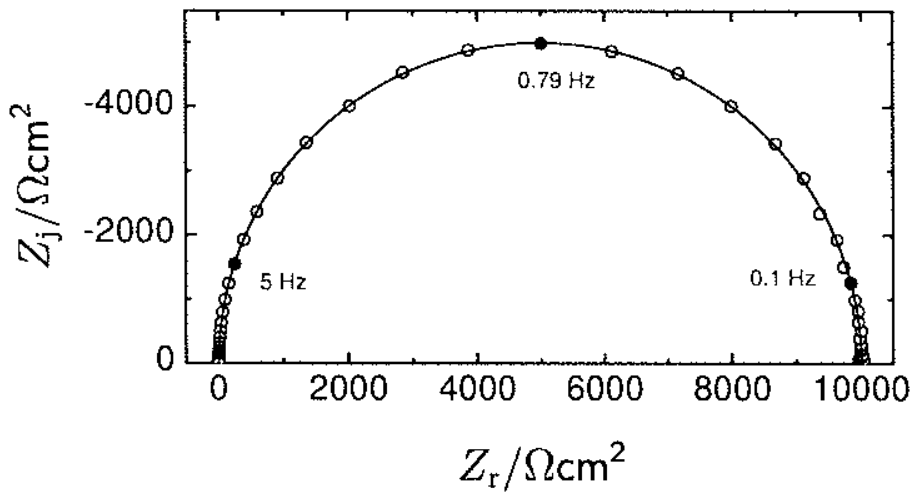

(a)

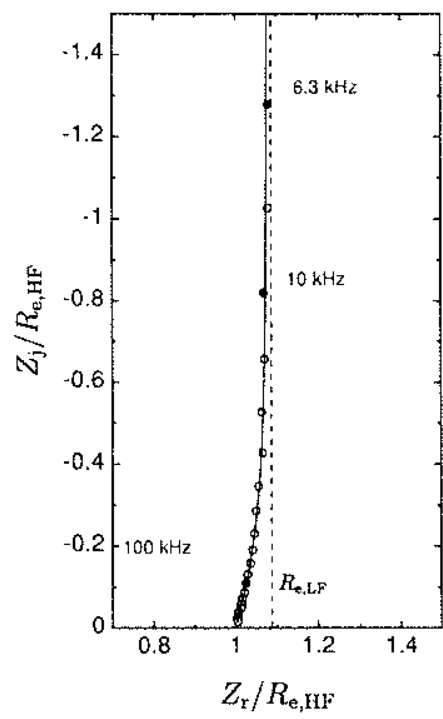

(b)

Figure 13: Simulated impedance response for a disk electrode with parameters $r_{0}=0.1 \mathrm{~cm}, p=12.67 \Omega \mathrm{cm}, \varepsilon=78, C_{\mathrm{dl}}=$ $20 \mu \mathrm{F} / \mathrm{cm}^{2}$, and $R_{t}=10^{4} \Omega \mathrm{cm}^{2}$. Nornally distributed stochastic error was added to the impedance with standard deviation chal to $0.2 \%$ of the modulus: a) full spectrum and b) scaled impedance in the high-frequency region. The line represents the fit by the measurement model witli thee Voigt elements and $\chi^{2} / \nu=0.94$

$19.50 \pm 0.40 \mu \mathrm{Fcm}^{-2}$, in good agreement with the input value of $20 \mu \mathrm{Fcm}^{-2}$. The charge-transfer resistance was $10,131 \pm 43 \Omega \mathrm{cm}^{2}$, in good agreement with the input value of $10,000 \Omega \mathrm{cm}^{2}$. The olnmic resistance of $8,268 \pm 45$ can be considered the low-frequency ohmic resistance $R_{c, L F}$. The ratio $R_{c, L F} / R_{c, H F}=1.053$ is less than the value of 1.08 calculated for capacitive behavior on disk electrodes ${ }^{56,55}$ and is in good agreement. with Figure 13.13 in Orazem and Tribollet ${ }^{41}$ for $J=4 R_{\mathrm{c}} / \pi R_{\mathrm{t}}=1$.

\subsection{Surface Distribution of Time Constants}

Newman showed, in 1966, that the electrode-insulator interface gives rise to nonuniform current and potentials distributions for currents that are below the mass-iransfer-limited current. ${ }^{57,58}$ Newman also reported that the capacity and ohmic resistance were functions of frequency above a critical value of frequency. ${ }^{56}$ Huang et al. ${ }^{55}$ showed that the geometry-induced frequency dispersion distorts the impedance response above a critical frequency. Hirschorn et al ${ }^{24}$ reported that the geometry induced frequency dispersion could be modeled approximately by a constant-phase element and that the Brug formula ${ }^{22}$ given as equation (2) provided a good means of extracting the capacitance from the resulting constant-phase-element parameters.

Synthetic data were obtained by finite-element solution of Laplace's equation for a disk electrode embedded in an insulating plane. The boundary condition for the electrode included the influence of a faradaic reaction. The numerical methods used were described by (xharbi et al. ${ }^{33}$ Normally distributed stochastic errors were added following equations (11) and (12). The resulting synthetic data are presented in Figure $13(\mathrm{a})$ for a disk electrode with parameters $r_{0}=0.1 \mathrm{~cm}, \rho=12.57 \Omega \mathrm{cm}, \varepsilon=78, C_{d !}=20 \mu \mathrm{F} / \mathrm{cm}^{2}$, and $R_{\mathrm{t}}=10^{4} \Omega \mathrm{cm}^{2}$. The influence of geometry-induced frequency dispersion is seen in Figure $13(\mathrm{~b})$.

The characteristic frequency associated with frequency dispersion was calculated from equation (42) to be $6.3 \times 10^{3} \mathrm{~Hz}$. Above this frequency, the nonuniform current and potential distributions associated with the electrode geometry causes frequency dispersion. The capacitance obtained by regression of the measurement model to the complete spectrum was $C=11.8 \pm 0.75 \mu \mathrm{F} / \mathrm{cm}^{2}$, substantially smaller than the input value of $20 \mu \mathrm{F} / \mathrm{cm}^{2}$. 


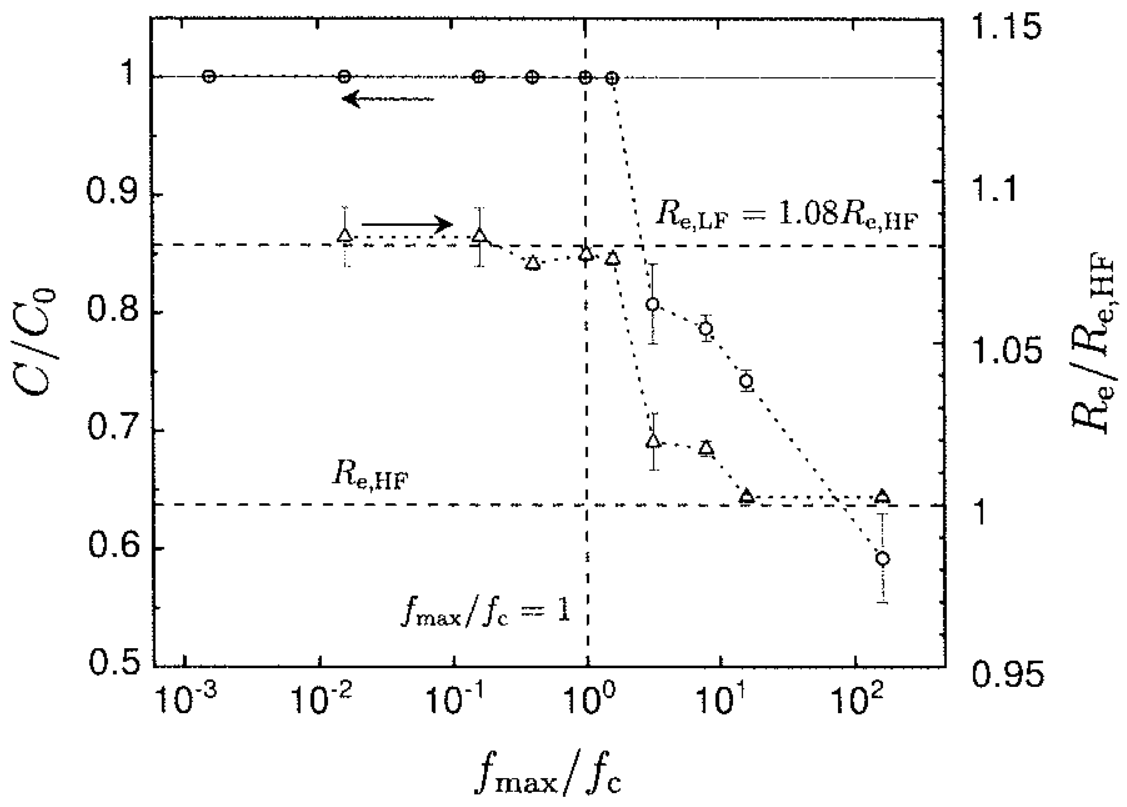

Figure 14: Scaled capacitance and scaled ohmic resistance obtained by regression of equation (6) to the complex impedance shown in Figure 13 for truncated frequency ranges as functions of the maximum frequency of the regressed data scaled to the characteristic frequency given by equation (42).

Table 8: Comparison of values extracted from the measurement model regression to the input parameters for the synthetic data presented in Figures 13 and 14.

\begin{tabular}{|c|c|c|c|}
\hline Parameter & Input & Measurement Model & Frequency Range \\
\hline$R_{\mathrm{e}, \mathrm{HF}} / \Omega \mathrm{cm}^{2}$ & 0.99472 & $0.99708 \pm 0.00084$ & $1 \mathrm{mHz}-1 \mathrm{MHz}$ \\
\hline$R_{\mathrm{t}} / \Omega \mathrm{cm}^{2}$ & 10,000 & $10,002.4 \pm 3.6$ & $1 \mathrm{mHz}-1 \mathrm{MHz}$ \\
\hline$C / \mu \mathrm{Fcm}^{-2}$ & 20 & $11.85 \pm 0.75$ & $1 \mathrm{mHz}-1 \mathrm{MHz}$ \\
\hline$R_{\mathrm{c}, \mathrm{LF}} / \Omega \mathrm{cm}^{2}$ & - & $1.0715 \pm 0.0019$ & $1 \mathrm{mHz}-6.31 \mathrm{kHz} z$ \\
\hline$R_{\mathrm{t}} / \Omega \mathrm{cm}^{2}$ & 10,000 & $10,002.0 \pm 3.8$ & $1 \mathrm{mHz}-6.31 \mathrm{kH} z$ \\
\hline$C / \mu \mathrm{Fcm}^{-2}$ & 20 & $19.996 \div 0.013$ & $1 \mathrm{mHz}-6.31 \mathrm{kHz}$ \\
\hline
\end{tabular}

The capacitance values obtained by regression of equation (6) to the complex impedance for truncated frequency ranges are presented in Figure 14 as functions of the maximum regressed frequency. Capacitance values were normalized by the input value for double-layer capacitance. A correct value for the capacitance was obtained for regression to a maximum frequency equal to that obtained by equation (42). Regression of the measurement model to the complete spectrum shown in Figure 13 required three Voigt elements, and regression to the truncated spectrum from $1 \mathrm{mHz}-6.31 \mathrm{kHz}$ required one Voigt element. The results are presented in Table 8.

Regression to maximum frequencies an order of magnitude larger than the characteristic frequency given by equation (42) yielded good estimates for the high-frequency ohmic resistance $R_{c, H F}$. Regression to maximum frequencies below the characteristic frequency yielded values of $R_{\mathrm{c}} / R_{6, \mathrm{HF}}$ that were close to the value of 1.08 calculated for $J=4 R_{\mathrm{c}} / \pi R_{\mathrm{t}}$ approaching zero. ${ }^{56,55,41}$ For the present simulations, $J=1.3 \times 10^{-4}$.

As the value of the ohmic resistance is much smaller than the charge-transfer resistance, both the regression to the complete spectrum and regression to the truncated spectrum yielded good approximations for the charge-transfer resistance. The regression to the $1 \mathrm{mHz}-6.31 \mathrm{kHz}$ frequency range yielded accurate values

for the double-layer capacitance because regression to a maximum frequency of $6.31 \mathrm{kHz}$ eliminated most of the confounding influence of the ohmic impedance. 


\section{Conclusions}

The measurement model provides a powerful tool for the identification of the error structure of impedance measurements, including determination of the frequency-dependent standard deviation of the measurements and the frequency range that is consistent with the Kramers-Kronig relations. The present work demonstrates that the measurement model also serves as a useful means to provide quantitative estimates for parameters relevant to impedance spectroscopy data, including ohmic resistance, polarization resistance, and capacitance.

The ability to extract capacitance by use of the measurement model is important, because most impedance systems show distributed-time-constant behavior that is often fit by use of the CPE. The CPE parameters are related to the capacitance of the electrode, but extraction of a capacitance requires different approaches depending on the nature of the underlying distribution. For example, the Brug formula ${ }^{22}$ is used in cases of a surface distribution of time constants, and the power-law model ${ }^{18,19}$ applies for a distribution through a film. Not all distributed-time-constant behaviors are represented by a CPE, and formulas like the Brug and Power-Law equations do not exist for such systems. Furthermore, the measurement model provides a unique ability to extract the high-frequency and low-frequency ohmic resistances for systems exhibiting an ohmic impedance.

The application of the measurement model to extract parameters for experimental impedance data depends on the nature of the electrochemical system under investigation. For systems that have a miform current and potential on the electrode surface, the ohmic resistance and capacitance may be extracted by regression of the measurement model to the part of the impedance spectrum that is found to be consistent with the Kramers-Kronig relations. The polarization resistance corresponding to the zoro-frequency limit may also be estimated. For systems that have a nonuniform current and potential distribution, a characteristic frequency can be identified above which the impedance is influenced by the associated frequency dispersion. This characteristic frequency may be estimated for general systems using

$$
f_{\mathrm{c}}=\frac{1}{2 \pi R_{0, \mathrm{HF}} C}
$$

where values of $C$ and $R_{\mathrm{c}, 13 \mathrm{f}}$ are estimated by regression of the measurement model to the impedance spectrum that is found to be consistent with the Kramers-Kronig relations. The estimate for $C$ may be updated be eliminating the frequencies above $f_{c}$. The new value of $C$ is used to calculate a new estimate for the characteristic frequency. This is an iterative process is completed when the estimated characteristic frequency is larger than the maximum frequency used in the regression. The iterative process will yield estimates for $C$ and $R_{e, L F}$. The iterative process may fail to yield a suitable convergence for cases in which $R_{\mathrm{t}}<R_{\mathrm{e}, \mathrm{HF}}$

The use of the measurement model to extract physical properties of electrochenical systems are guided by four caveats:

1. In the presence of geometry-induced frequency dispersion, the capacitance obtained by the measurement model was smaller than the input double-layer capacitance. The measurement model can be made to yield an accurate capacitance by removing the contribution of the ohmic impedance from the regressed data.

2. High-frequency and low-frequency ohmic resistances are defined for systems showing the presence of geometry-induced frequency dispersion. The low-frequency ohmic resistance may be quantified by regression to data that are below the characteristic frequency defined by equation (42).

3. For systems that exhibit the infuence of geometric capacitance, the capacitance obtained by the measurement model is the geometric capacitance, independent of the value of the double layer capacitance. The double-layer capacitance and low-frequency ohmic resistance may be extracted from regression to data that are below the characteristic frequency defined by equation (42). The high-frequency ohmic resistance may be obtained by regression to data that are at frequencies below that affected by the geometric capacitance loop.

4. For systems that show pure constant-phase-element behavior, a capacitance cannot be identified, either by the measurement model or by extrapolation of the Cole-Cole plot. 
Used wisely, the measurement model may be a powerful tool for extracting the capacitance, ohmic resistance, and polarization resistance for impedance data. It can be applied both for systems exhibiting normal distributions of time constants and, if applied to frequencies sufficiently below the characteristic frequency for geometry-induced dispersion, for systems showing surface distributions of time-constants. Used in this way, the measurement model provides a powerful complement to the development of system-specific process models.

\section{Acknowledgments}

Mark Orazem acknowledges financial support from the University of Florida Foundation Preeminence and the Dr. and Mrs. Frederick C. Edie term professorships.

\section{References}

[1] P. Agarwal, M. E. Orazem, L. H. García-Rubio, Measurement models for electroclemicaj impedance spectroscopy: 1. Demonstration of applicability, Journal of the Electrochemical Society 139 (1992) $1917-1927$.

[2] P. Agarwal, O. D. Crisalle, M. E. Orazem, L. H. García-Rubio, Measurement models for electrochemical impedance spectroscopy: 2. Determination of the stochastic contribution to the error structure, Journal of the Electrochemical Society 142 (1995) 4149-4158.

3 P. Agarwal, M. E. Orazem, L. H. García Rubio, Application of the kramers kronig relations to electrochenical impedance spectroscopy, in: J. Scully, D. Silverman, M. Kendig (Eds.), Electroclemical Impedance: Analysis and Interpretation, Vol. ASTM STP 1188, American Society for Testing and Materials, Philadelphia, 1993, pp. 115 -139.

(4) P. Agarwal, M. E. Orazem, L. H. García-Rubio, Measurement models for electrochemical impedance spectroscopy: 3. Evaluation of consistency with the kramers-kronig relations, Joumal of the Electrochemical Society $142(1995)$ 4159-4168.

[5] M. Schönleber, E. Ivers-Tiffée, Approximability of impedance spectra by rc elements and

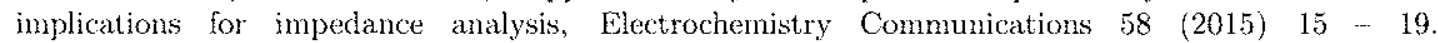
doi:htups://doi.org/10.1016/j.elecom.2015.05.018.

URL http://ww. sciencedirect.com/science/article/pii/S1388248115001502

[6] B. A. Boukamp, J. R. Macdonald, Alternatives to kronig-kramers transformation and testing, and estimation of distributions, Solid State Ionics 74 (1994) 85-101.

[7] B. A. Bolkamp, A linear kronig-kramers transform test for immittance data validation, Journal of the Electrochemical Society 142 (1995) $1885-1894$.

[8] M. Schönleber, D. Klotz, E. Ivers-Tiffée, A method for improving the robustness of linear KramersKronig validity iests, Electrochimica Acta 131 (2014) 20-27, electrochemical Impedance Spectroscopy.

[9] L. Pauwels, W. Simons, A. Hubin, 3. Schoukens, R. Pintelon, Key issues for reproducible impedance measurements and their wellfounded error analysis in a silver electrodeposition system, Electrochimica Acta 47 (2002) 2135-2141.

[10] O. Blajiev, T. Breugelmans, R. Pintelon, A. Hubin, Improvement of the impedance measurement reliability by some new experimental and data treatment procedures applied to the behavior of copper in neutral chloride solutions containing small heterocycle molecules, Electrochimica Acta 51 (8-9) (2006) 1403-1412. doi:10.1016/j.electacta.2005.02.113.

[11] R. Pintelon, J. Schoukens, System Identification: A Frequency Domain Approach, John Wiley \& Sons, 2001 . 
[12] P. K. Shukla, M. E. Orazem, O. D. Crisalle, Validation of the measurement model concept for error structure identification, Electrochimica Acta 49 (2004) 2881--2889.

[13] C. You, M. A. Zabara, M. E. Orazem, B. Ulgut, Application of the kramers-kronig relations to multi-sine electrochemical impedance measurements, Journal of The Electrochemical Society 167 (2020) 020515.

[14] M. E. Orazem, P. T. Wojcik, M. Durbha, I. Frateur, L. H. García-Rubio, Application of measurement models for interpretation of impedance spectra for corrosion, Materials Science Forum 289-292 (1998) $813-828$.

[15] C. Cleveland, S. Moghaddam, M. E. Orazen, Nanometer-scale corrosion of copper in deaerated deionized water, Journal of the Electrochemical Society 161 (3) (2014) C107-C114. arXiv:littp://jes.ecsdl.org/content/161/3/C107.full.pdif-html, doi:10.1149/2.030403jes. URL http://jes.ecsdl org/content/161/3/C107.abstract

[16] M. E. Orazem, P. K. Shukla, M. A. Membrino, Extension of the measurement model approach for deconvolution of underlying distributions for impedance measurements, Electrochimica Acta 47 (2002) $2027-2034$.

[17] Y.-M. Chen, A. S. Nguyen, M. E. Orazem, B. 'Tribollet, N. Pébère, M. Musiani, V. Vivier, ldentification of resistivity distributions in dielectric layers by measurement model analysis of impedance spectroscopy, Electrochimica Acta 219 (2016) 312-320. doi:https://doi.org/10.1016/j.electacta.2016.09.136.

18 B. Hirschorn, M. E. Orazem, B. Tribollet, V. Vivier, I. Frateur, M. Musiani, Constant-phase-element behavior caused by resistivity distributions in films: 1. Theory, Joumal of the Electrochemical Society 157 (2010) C452-C457.

[19] B. Hirschorn, M. E. Orazem, B. Tribollet, V. Vivier, I. Frateur, M. Musiani, Constant-phase-element behavior caused by resistivity distributions in films: 2. Applications, Journal of the Electrochemical Society 157 (2010) C458-C463.

[20] P. Córdoba-Torres, T. J. Mesquita, O. Devos, B. Tribollet, V. Roche, R. P. Nogueira, On the intrinsic coupling between constant-phase element parameters $\alpha$ and $q$ in electrochemical impedance spectroscopy, Electrochimica Acta 72 (2012) 172-178.

21 J.-B. Jorcin, M. E. Orazem, N. Pébère, B. Tribollet, CPE analysis by local electrochemical impedance spectroscopy, Electrochimica Acta 51 (2006) 1473-1479.

[22] G. J. Brug, A. L. G. van den Eeden, M. Sluyters-Rehbach, J. H. Sluyters, The analysis of electrode impedances complicated by the presence of a constant phase element, Journal of Electroanalytical Chemistry 176 (1984) 275-295.

[23] M. E. Orazem, B. Tribollet, V. Vivier, S. Marcelin, N. Pébère, A. L. Bunge, E. A. White, D. P. Riemer, I. Frateur, M. Musiani, Dielectric properties of materials showing constant-phase-element (CPE) impedance response, Journal of the Electrochemical Society 160 (2013) C215-C225.

[24] B. Hirschorn, M. E. Orazem, B. Tribollet, V. Vivier, I. Frateur, M. Musiani, Deternination of effective capacitance and film thickness from cpe parameters, Electrochimica Acta 55 (2010) 6218-6227.

[25] C. H. Hsu, F. Mansfeld, Technical note: Concerning the conversion of the constant phase element parameter $Y_{0}$ into a capacitance, Corrosion 57 (2001) 747-748.

[26] Y.-M. Chen, N. G. Rudawski, E. Lambers, M. E. Orazem, Application of impedance spectroscopy and surface analysis to obtain oxide fim thickness, Journal of the Electrochemical Society 164 (2017) C563-C573.

[27] S. Chakri, 1. Frateur, M. E. Orazem, E. M. M. Sutter, T. T. M. Tran, B. Tribollet, V. Vivier, Improved EXS analysis of the electrochemical behaviour of carbon steel in alkaline solution, Electrochimica Acta 246 (2017) 924-930. 
[28] S. Amand, M. Musiani, M. E. Orazem, N. Pébère, B. Tribollet, V. Vivier, Constant-phase-element behavior caused by inhomogeneous water uptake in anti-corrosion coatings, Electrochimica Acta 87 (2013) 693-700.

[29] M. Musiani, M. E. Orazem, N. Pébère, B. Tribollet, V. Vivier, Determination of resistivity profiles in anti-corrosion coatings from constant-phase-element parameters, Progress in Organic Coatings 77 (2014) 2076-2083.

[30] A. S. Nguyen, M. Musiani, M. E. Orazem, N. Pébère, B. Tribollet, V. Vivier, Impedance analysis of the distributed resistivity of coatings in dry and wet conditions, Electrochimica Acta 179 (2015) $452 \cdots 459$.

[31 A. S. Nguyen, M. Musiani, M. E. Orazem, N. Pébère, B. Tribollet, V. Vivier, Impedance study of the infuence of chromates on the properties of waterborne coatings deposited on 2024 aluminium alloy, Corrosion Science 109 (2016) 174-181.

[32] A. S. Nguyen, N. Causse, M. Musiani, M. E. Orazem, N. Pébère, B. Tribollet, V. Vivier, Determination of water uptake in organic coatings deposited on 2024 aluminium alloy: Comparison between impedance measurements and gravimetry, Progress in Organic Coatings 112 (2017) 93 100.

[33] O. Gharbi, A. Dizon, M. E. Orazen, M. T. T. Tran, B. Tribollet, V. Vivier, From frequency dispersion to olmic impedance: A new insight on the high-frequency impedance analysis of electrochemical systems, Electrochimica Acta 320 (2019) 134609. doithttps://doi.org/10.1016/j.electacta.2019.134609.

[34] L. Young, Anodic oxide films 4: The interpretation of impedance measurements on oxide coated electrodes on niobium, Transactions of the Faraday Society 51 (1955) 1250-1260.

[35] L. Young, Anodic Oxide Films, Acadenic Press, New York, 1961.

[36] K. S. Cole, R. H. Cole, Dispersion and absorption in dielectrics 1: Alternating current characteristics, Journal of Chemical Physics 9 (4) (1941) 341-351.

[37] K. S. Cole, R. H. Cole, Dispersion and absorption in dielectrics 2: Direct current characteristics, Journal of Chemical Physics 10 (2) (1942) 98-105.

[38] T. Jänsch, J. Wallauer, B. Roling, Influence of electrode roughness on double layer formation in ionic liquids, The Journal of Physical Chemistry C 119 (2015) 4620-4626. arXiv:htip://dx.doi.org/10.1021/jp512617j.

[39] M. Benoit, C. Bataillon, B. Gwinner, F. Miserque, M. E. Orazem, C. M. Sánchez-Sánchez, B. Tribollet, V. Vivier, Comparison of different methods for measuring the passive film thickness on metals, Electrochinica Acta 201 (2016) 340)-347.

[40] Y. Sakamoto, M. Ishiguso, G. Kitigawa, Akaike Information Criterion Statistics, D. Reidel, Boston, 1986.

[41] M. E. Orazem, B. Tribollet, Electrochemical Impedance Spectroscopy, 2nd Edition, John Wiley \& Sons, Hoboken, 2017.

[42] S. L. Carson, M. E. Orazem, O. D. Crisalle, L. H. Garcia-Rubio, On the error structure of impedance measurements: Simulation of frequency response analysis (fra) instrumentation, Journal of the Electrochemical Society 150 (2003) E477-E490.

[43] A. N. Jansen, P. T. Wojcik, P. Agarwal, M. E. Orazem, Thermally stimulated deep-level impedance spectroscopy: Application to an n-gaas schottky diode, Joumal of the Electrochemical Society 143 (1996) 4066-4074.

44] S. L. Carson, M. E. Orazem, O. D. Crisalle, L. H. García-Rubio, On the error structure of impedance measurements: Simulation of phase sensitive detection (psd) instrumentation, Journal of the Electrochemical Society 150 (2003) E491- E500. 
[45] S. K. Roy, M. E. Orazem, Error analysis for the impedance response of pem fuel cells, Journal of the Electrochemical Society 154 (8) (2007) B883-B891.

[46] W. Watson, M. E. Orazem, A Python-based measurement model toolbox for impedance spectroscopy, Tech. rep., University of Florida (2020).

[47] S. Havriliak, S. Negami, A complex plane representation of dielectric and mechanical relaxation processes in some polymers, Polymer 8 (1967) 161--210.

[48] B. A. Boukamp, Derivation of a distribution function of relaxation times for the (fractal) finite length warburg., Electrochimica Acta 252 (2017) 154-163.

[49] H. Göhr, Contributions of single electrode processes to the impedance, Berichte der Bunsengesellschaft für physikalische Chemie 85 (1981) 274-280.

[50] H. Göhr, J. Schaller, C. A. Schiller, Impedance studies of the oxide layer on zircaloy after previous oxidation in water vapor at $400^{\circ} \mathrm{C}$, Electrochimica Acta 38 (14) (1993) $1961 \cdots 1964$.

[51] A. R. Dizon, M. E. Orazem, On the impedance response of interdigitated electrodes, Electrochimica Acta 327 (2019) 135000. doi:https://doi.org/10.1016/j.electacta.2019.135000.

[52] J. C. Maxwell, A Treatise on Electricity and Magnetism, Vol. 1, Clarendon Press, Oxford, 1873.

53 K. N. Allahar, D. P. Butt, M. E. Orazem, H. A. Chin, G. Danko, W. Ogden, R. E. Yungk, Impedance of steels in new and degraded ester-based lubricating oil, Electrochimica Acta 5̃ (2006) 1497-1504.

[54] V.F. Lvovich, M. F. Smiechowski, AC impedance investigation of conductivity of automotive lubricants using two- and four-electrode electrochemical cells, Journal of Applied Electrochemistry 39 (12) (2009) 2439 .

[55] V. M.-W. Huang, V. Vivier, M. E. Orazem, N. Pébère, B. Tribollet, The apparent CPE behavior of an ideally polarized blocking electrode: A global and local impedance analysis, Journal of the Electrochemical Society 154 (2007) C81-C88.

[56] J. S. Newman, Frequency dispersion in capacity measurements at a disk electrode, Journal of the Electrochemical Society 117 (1970) 198-203.

[57] J. S. Newman, Resistance for flow of current to a disk, Joumal of the Electrochemical Society 113 (5) (1966) 501-502.

[58] J. S. Newman, Current distribution on a rotating disk below the limiting current, Journal of the Electrochemical Society 113 (1966) 1235-1241. 


\section{List of Figures}

1 A schematic representation of a Voigt circuit used by Agarwal et al. ${ }^{1,2,4}$ as a measurement model. . . . . . . . . . . . . . . . . . . . . . . .

2 Schematic representation of an electrochenical electrode-electrolyte interface: a) electrode with a miform current and potential distribution and b) electrode with a nonuniform geometryinduced current and potential distribution. . . . . . . . . . . . . . .

3 Regression results for synthetic data obtained using the parameters given in Table 1 at three quarters of the mass-transfer-limited current. The line represents the fit of the measurement model with parameters given in Table $2 \ldots \ldots \ldots \ldots \ldots \ldots$

4 Normalized residual errors for the regression shown in Figure 3 with parameters shown in Table 2: a) real part of the impedance and b) imaginary part of the impedance. Dashed lines represent the $95.4 \%$ interval for the assumed stochastic error structure i.e. $\pm 2 \sigma / Z_{\mathrm{r}}$ or

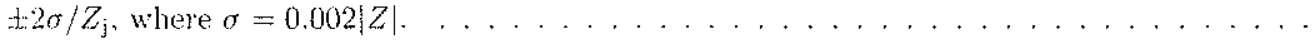

5 Complex capacitance obtained from the impedance data shown in Figure 3 with assumed ohmic resistance as a parameter. The maximum frequency shown is $100 \mathrm{kHz}$. . . . . . . . .

6 Complex capacitance obtained from the impedance data shown in Figure 3. The maximum frequency shown is $10 \mathrm{kHz}$. An asymptotic approach at high frequencies yields a capacitance near $20 \mu \mathrm{F} / \mathrm{cm}^{2}$. The line is the fit by a modified measurement model given as equation (18) to frequencies between $1 \mathrm{~Hz}$ and $10 \mathrm{kHz} \ldots \ldots \ldots \ldots \ldots \ldots$

7 Regression results for synthetic data obtained using the parameters given in Table 1 at three quarters of the mass-transfer-limited current. The data were truncated to minimize the contribution of the diffusion impedance. The frequency range was $1-100 \mathrm{kHz}$, and $\chi^{2} / 1=0.86$. The line represents the fit of the measurement model with parameters given in Table $4 . \quad$. .

8 Young impedance given by equation (21) in Nyquist format with $R_{\mathrm{e}}=10 \Omega \mathrm{cm}^{2}, \varepsilon=12$, $\lambda=2 \mathrm{~nm}, \delta=4 \mathrm{~nm}$, and $\rho_{0}=10^{10} \Omega \mathrm{cm}$. The line represents the measurement model fit with three Voigt elements. The dashed line represents a perfect $R C$ behavior and is presented to highlight the distortion caused by the Young resistivity distribution. The frequency range was $10 \mathrm{mHz}$ to $100 \mathrm{kHz}$ and $x^{2} / 1=1.23 \ldots \ldots \ldots \ldots$

9 Impedance given by equations (30) and (19) for the resistivity given by equation (27) with $R_{\mathrm{c}}=10 \Omega \mathrm{cm}^{2}, \rho_{0}=10^{14} \Omega \mathrm{cm}, \rho_{\delta}=5 \times 10^{6} \Omega \mathrm{cm}, \gamma=6+2 / 3, \varepsilon=12$, and $\delta=2 \mathrm{~nm}$ : a) complete frequency range and $b$ ) high frequency range. The line represents the measurement model fit with eleven Voigt elements. The frequency range was $10 \mathrm{mHz}$ 1.0 $100 \mathrm{kHz}$ and

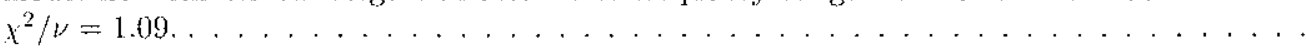

10 Capacitance obtained by regression of equation (6) to the complex impedance for truncated frequency ranges as functions of the maximum regression frequency of the regressed data. For example, the values of capacitance and ohmic resistance for a maximum regression frequency of $100 \mathrm{~Hz}$ were obtained by regression to data encompassing the frequency range of $10 \mathrm{mHz}$

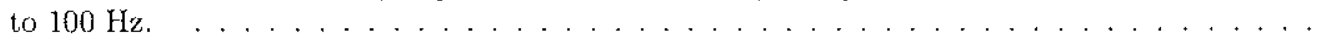

11 Simulated impedance response for a disk electrode with parameters $r_{0}=0.1 \mathrm{~cm}, \rho=10^{5} \Omega \mathrm{cm}$, $\varepsilon=78, C_{\mathrm{d} 1}=20 \mu \mathrm{F} / \mathrm{cm}^{2}$, and $R_{t}=10^{4} \Omega \mathrm{cm}^{2}$. The line represents the fit by the measurement inodel with four Voigt elements. The frequency range was $1 \mathrm{mHz}-1 \mathrm{MHz}$, and $\chi^{2} / \nu=1.29$.

12 Truncated impedance taken from Figure 11: a) synthetic data with a frequency range of $1 \mathrm{mHz}$ to $100 \mathrm{~Hz}$ and b) synthetic data with a frequency range of $1 \mathrm{mHz}$ to $0.79 \mathrm{~Hz}$. The lines represent measurement model fits using; respectively, three or one Voigt element, and the respective values of $\chi^{2} / \nu$ were 1.14 and $1.06 \ldots \ldots \ldots \ldots$ 
13 Simulated impedance response for a disk electrode with parameters $r_{0}=0.1 \mathrm{~cm}, \rho=12.67 \Omega 2 \mathrm{~cm}$, $\varepsilon=78, C_{\mathrm{al}}=20 \mu \mathrm{F} / \mathrm{cm}^{2}$, and $R_{t}=10^{4} \Omega \mathrm{cm}^{2}$. Normally distributed stochastic error was added to the impedance with standard deviation equal to $0.2 \%$ of the modulus: a) full spectrum and b) scaled impedance in the high-frequency region. The line represents the fit by the measurement model with three Voigt elements and $x^{2} / \nu^{\prime}=0.94$.

14 Scaled capacitance and scaled ohmic resistance obtained by regression of equation (6) to the complex impedance shown in Figure 13 for truncated frequency ranges as functions of the maximum frequency of the regressed data scaled to the characteristic frequency given by equation (42)

\section{List of Tables}

1 Parameters employed for the electrochemical reaction infuenced by mass transfer in a film

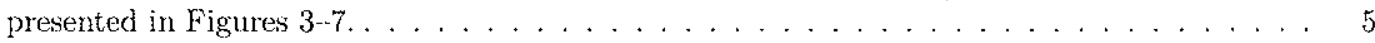

2 Regression results for the synthetic data shown in Figure 3. The characteristic frequency for each element is defined as $f_{\mathrm{k}}=1 /\left(2 \pi \tau_{\mathrm{k}}\right) \ldots \ldots \ldots \ldots \ldots \ldots$

3 Comparison of values extracted from the measurement model regression to the input parameters for the synthetic data presented in Figures 3, 5, and 7. Input parameters are given in

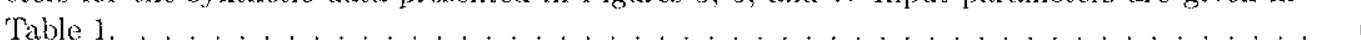

4 Regression results for a truncated spectrum shown in Figure 7. Input parameters for $R_{0}$ (see $R_{0}$ ) and $R_{\mathrm{t}}$ (see $R_{1}$ ) are given in Table $1 \ldots \ldots \ldots \ldots \ldots$

5 Comparison of values extracted from the measurement model regression to the input parameters for the synthetic data presented in Figure $8 \ldots \ldots \ldots \ldots$. . . . . . . . . . . . .

6 Comparison of values extracted from the measurement model regression to the input parameters for the synthetic data presented in Figure $9 \ldots \ldots \ldots \ldots \ldots$. . . . . . . . . 12

7 Comparison of values extracted from the measurement model regression to the input parameters for the synthetic data presented in Figures 3,5 , and $7 \ldots \ldots \ldots \ldots$

8 Comparison of values extracted from the measurement model regression to the input parameters for the synthetic data presented in Figures 13 and 14. 